\title{
Speed of sound in pure fatty acid methyl esters and biodiesel fuels
}

\author{
André F.G. Lopes ${ }^{a}$, Maria del Carmen Talavera-Prieto ${ }^{b}$, Abel G.M. Ferreira ${ }^{\text {b,* }}$, Jaime B. Santos ${ }^{a}$, \\ Mário J. Santos ${ }^{\mathrm{a}}$, António T.G. Portugal ${ }^{\mathrm{b}}$ \\ ${ }^{a}$ Department of Electrical and Computers Engineering, University of Coimbra, Polo II, Rua Silvio Lima, 3030-970 Coimbra, Portugal \\ ${ }^{\mathrm{b}}$ Department of Chemical Engineering, University of Coimbra, Polo II, Rua Silvio Lima, 3030-970 Coimbra, Portugal
}

\section{H I G H L I G H T S}

- New data on sound speed is reported for fatty acid methyl esters.

- New data on speed of sound is reported for biodiesel fuels.

- Molar compressibility was calculated for fatty acid methyl esters and biodiesel.

- Predictive models for speed of sound and molar compressibility are proposed.

\section{A R T I C L E I N F O}

\section{Article history:}

Received 7 June 2013

Received in revised form 12 July 2013

Accepted 16 July 2013

Available online 31 July 2013

\section{Keywords:}

Biodiesel

Speed of sound

Compressibility

Correlation

\begin{abstract}
A B S T R A C T
The property changes associated with the differences in chemical composition of biodiesel may change the fuel injection timing which in turn cause different exhaust emissions and performance of engines. The property that has an important effect on the fuel injection timing is the speed of sound (related with isentropic bulk modulus). Despite the speed of sound of pure fatty acid (methyl and ethyl) esters being reasonably known in a wide range of temperature the experimental data for biodiesel are very scarce in the literature. In this work the speed of sound of six fatty acid methyl esters (FAME = laurate (MeC12:0), myristate (MeC14:0), palmitate (MeC16:0), stearate (MeC18:0), oleate (MeC18:1), linoleate (MeC18:2)) and six biodiesel fuel samples were measured using a non-intrusive ultrasonic methodology. The measurements for FAMEs were made at atmospheric pressure from a minimum of $288.15 \mathrm{~K}$ to a maximum of $353.15 \mathrm{~K}$, and in the temperature range $298.15-353.15 \mathrm{~K}$ for biodiesel samples. The uncertainty of the measurements was estimated as less than $\pm 1 \mathrm{~m} \mathrm{~s}^{-1}$. The speed of sound data combined with available density data from literature was used to calculate the isentropic compressibility and the molecular compressibility for the FAMEs and for the biodiesel samples. The results for molecular compressibility evidenced that this property is almost independent of the temperature in the temperature range of calculations both for FAMES and biodiesel. Linear relationships were established between the molar compressibility and the molecular weight for FAMES and biodiesel. The before mentioned behavior of molar compressibility face to temperature and molecular weight make it possible to develop prediction methods for the calculation of the speed of sound.
\end{abstract}

(c) 2013 Elsevier Ltd. All rights reserved.

\section{Introduction}

The conventional fossil fuels (petrofuels) are non-renewable, increasingly scarce, with growing emissions of combustion resulting pollutants, and with increasing costs of production. On the other hand, fuel reserves are concentrated in certain planet regions and most of them are reaching the production peak. All these circumstances make biomass sources more attractive in particular the biodiesel. Unlike petrodiesel, biodiesel is a renewable fuel offering important benefits including reduction of green-house

\footnotetext{
* Corresponding author. Tel.: +351 239798 729; fax: +351 239798703 .

E-mail address: abel@eq.uc.pt (A.G.M. Ferreira).
}

emissions, biodegradability, and non-toxicity. Biodiesel shows total miscibility with petrodiesel and compatibility with modern engines [1,2]. Nowadays, biodiesel production has important economic and social impacts at the regional development level especially to developing countries [3]. Technically, biodiesel is a fuel formed by long chain of fatty acid esters produced from a large variety of feedstocks including vegetable oils and animal fats, with designation of $\mathrm{B} 100$, meeting the property and quality requirements of the American Society Testing (ASTM) D6751 standard. Biodiesel can be produced through transesterification chemical reaction along which the raw material reacts with alcohol (usually methanol or ethanol) in the presence of a catalyst that can be metal alkoxide [4], ionic liquids [5], or others [6]. The resulting products 
are the fatty acid (methyl or ethyl) esters (FAE or biodiesel) and glycerol.

Glycerol, which is a high value byproduct of the transesterification reaction forms one phase and (FAE) form another phase, which settles above the glycerol in the reactor. The biodiesel fuel must meet specifications contained in biodiesel standards, such as the (ASTM) D6751 and the EN14214 in Europe. Some of these specifications are related to the fuel quality such as completeness of transesterification reaction, storage conditions and other important properties as viscosity, density, oxidative stability, cetane number, and cold flow properties, depending all on the fatty acid composition of biodiesel. The injection process is of great importance for engine efficiency. In this process an appropriate quantity of fuel is feed to the engine cylinder forming a spray of tiny fuel droplets to optimize the combustion and reduce the fuel consumption and emissions. All injection process is strongly influenced by the thermophysical fuel properties. The properties of major influence in the injection time are the surface tension [7], the viscosity, and the isentropic bulk modulus [8], which is determined by the sound speed. Therefore, for the accurate design and maintenance of injection systems, the accurate knowledge of the sound speed of the fuel plays an important role. Biodiesel sound speed information is very scarce in the literature, although several authors have measured this property for pure methyl and ethyl FAEs. Some previous literature reports on speed of sound of pure FAMEs and biodiesel are summarized in Table 1, calculated for different temperature and pressure ranges, techniques and uncertainties of the measurements.

This work aims to evaluate the sound speed of pure liquid FAMEs most frequently found in biodiesel, and also of the biodiesel fuels. This property has been measured for MeC12:0, MeC14:0, MeC16:0, MeC18:0, MeC18:1, MeC18:2 considering wide ranges

Table 1

Previous sources of data for the speed of sound of the FAME compounds studied herein and biodiesel.

\begin{tabular}{|c|c|c|c|c|c|c|c|}
\hline Authors & Year & $N_{p}$ & $T(\mathrm{~K})$ & $P(\mathrm{MPa})$ & $(u)$ and $\left(\sigma_{u}\left(\mathrm{~m} \mathrm{~s}^{-1}\right)^{\mathrm{a}}\right.$ & Method $^{\mathrm{b}}$ & Purity (wt\%) \\
\hline \multicolumn{8}{|l|}{ Mehyl laurate (MeC12:0) } \\
\hline Gouw and Vlugtert [9] & 1964 & 2 & 293,313 & 0.1 & $(1278,1351)(0.08 \%)$ & Interf & $>99.7$ \\
\hline Tat and Gerpen $[10]^{\mathrm{C}}$ & 2003 & - & $293-373$ & $0.1-32.5$ & $(1086-1502)(0.1-0.7 \%)$ & $\mathrm{PE}$ & d \\
\hline Tat and Gerpen, NREL[11] & 2003 & 30 & $293-373$ & $0.1-34.5$ & $(1080-1498)(0.1-0.7 \%)$ & $\mathrm{PE}$ & d \\
\hline Freitas et. al. [12] & 2013 & 12 & $288-343$ & 0.1 & $(1171-1370)(0.01)$ & PE & 97 \\
\hline \multicolumn{8}{|l|}{ Methyl myristate (MeC14:0) } \\
\hline Gouw and Vlugtert [9] & 1964 & 2 & 293,313 & 0.1 & $(1299,1372)(0.08 \%)$ & Interf & $>99.7$ \\
\hline Freitas et. al. [12] & 2013 & 10 & $298-343$ & 0.1 & $(1194-1353)(0.01)$ & $\mathrm{PE}$ & 98 \\
\hline Daridon et. al. [13] & 2013 & 8 & $303-373$ & 0.1 & $(1098-1335)(<0.1 \%)$ & PE & 99 \\
\hline Ndiaye et al. [14] & 2013 & 53 & $303-393$ & $0.1-80$ & $(1036-1614)(0.2 \%)$ & $\mathrm{PE}$ & 99 \\
\hline \multicolumn{8}{|l|}{ Methyl palmitate (MeC16:0) } \\
\hline Gouw and Vlugtert [9] & 1964 & 1 & 313 & 0.1 & $(1318)(0.08 \%)$ & Interf & $>99.7$ \\
\hline Tat and Gerpen $[10]^{\mathrm{C}}$ & 2003 & - & $293-373$ & $0.1-32.5$ & $(1123-1537)(0.1-0.7 \%)$ & $\mathrm{PE}$ & $>99$ \\
\hline Tat and Gerpen, NREL[11] & 2003 & 24 & $313-373$ & $0.1-34.5$ & $(1019-1463)(0.1-0.7 \%)$ & PE & e \\
\hline Ott et al. [15] & 2008 & 7 & $308-338$ & 0.1 & $(1233-1338)(0.1 \%)$ & $\mathrm{PE}$ & $>99.0$ \\
\hline Daridon et. al. [13] & 2013 & 7 & $313-373$ & 0.1 & $(1171-1370)(<0.1 \%)$ & $\mathrm{PE}$ & 99 \\
\hline Ndiaye et al. [14] & 2013 & 35 & $303-393$ & $0.1-50$ & $(1057-1507)(0.2 \%)$ & PE & 99 \\
\hline Freitas et al. [16] & 2013 & 8 & $308-343$ & 0.1 & $(1216-1337)(0.02)$ & DSA5000 & 99 \\
\hline \multicolumn{8}{|l|}{ Methyl Stearate (MeC18:0) } \\
\hline Gouw and Vlugtert [9] & 1964 & 1 & 313 & 0.1 & $(1333)(0.08 \%)$ & Interf & $>99.7$ \\
\hline Tat and Gerpen $[10]^{\mathrm{C}}$ & 2003 & - & $293-373$ & $0.1-32.5$ & $(1141-1541)(0.1-0.7 \%)$ & $\mathrm{PE}$ & $>99$ \\
\hline Ott et al. [15] & 2008 & 5 & $318-338$ & 0.1 & $(1248-1317)(0.1 \%)$ & PE & $>99.0$ \\
\hline Freitas et al. [16] & 2013 & 7 & $313-343$ & 0.1 & $(1231-1333)(0.02)$ & DSA5000 & 99 \\
\hline \multicolumn{8}{|l|}{ Methyl oleate (MeC18:1) } \\
\hline Gouw and Vlugtert [9] & 1964 & 2 & 293,313 & 0.1 & $(1338-1408)(0.08 \%)$ & Interf & $>99.7$ \\
\hline Ott et al. [15] & 2008 & 7 & $278-338$ & 0.1 & $(1250-1462)(0.1 \%)$ & $\mathrm{PE}$ & $>99.0$ \\
\hline Freitas et. al. [12] & 2013 & 12 & $288-343$ & 0.1 & $(1238-1427)(0.01)$ & $\mathrm{PE}$ & 99 \\
\hline Daridon et. al. [13] & 2013 & 10 & $283-373$ & & $(1139-1446)(<0.1 \%)$ & PE & 99 \\
\hline \multicolumn{8}{|l|}{ Methyl linoleate (MeC18:2) } \\
\hline Gouw and Vlugtert [9] & 1964 & 2 & 293,313 & 0.1 & $(1348-1419)(0.08 \%)$ & Interf & $>99.7$ \\
\hline Tat and Gerpen $[10]^{\mathrm{C}}$ & 2003 & - & $293-373$ & $0.1-32.5$ & $(1156-1554)(0.1-0.7 \%)$ & $\mathrm{PE}$ & f \\
\hline Tat and Gerpen, NREL[11] & 2003 & 30 & $293-373$ & $0.1-34.5$ & $(1151-1550)(0.1-0.7 \%)$ & $\mathrm{PE}$ & f \\
\hline Ott et al. $[15]$ & 2008 & 7 & $278-338$ & 0.1 & $(1260-1472)(0.1 \%)$ & $\mathrm{PE}$ & $>99.0$ \\
\hline Daridon et. al. [13] & 2013 & 10 & $283-373$ & 0.1 & $(1149-1456)(<0.1 \%)$ & PE & 99 \\
\hline Freitas et al. [16] & 2013 & 11 & $288-343$ & 0.1 & $(1246-1418)(0.02)$ & DSA5000 & 99 \\
\hline \multicolumn{8}{|l|}{ Biodiesel } \\
\hline Tat and Gerpen $[10,11]$ & 2003 & 384 & $293-373$ & $0.1-34.5$ & $(1053-1551)(0.1-0.7 \%)$ & $\mathrm{PE}$ & - \\
\hline Huber et al. [17] & 2009 & 14 & $278-333$ & 0.08 & $(1255-1467)(0.03-1.00)$ & $\mathrm{PE}$ & $\mathrm{g}$ \\
\hline Payri et al. $[18]^{\mathrm{C}}$ & 2011 & - & $298-343$ & $15-180$ & $(1213-1848)(\approx 0.3 \%)$ & TOF & $\mathrm{h}$ \\
\hline Nicolic et al. [19] ${ }^{\mathrm{C}}$ & 2012 & 17 & 293 & $0.1-160$ & $(1404-1893)(0.05)$ & PE & $\mathrm{i}$ \\
\hline Freitas et al. [12] & 2013 & 120 & $288-343$ & 0.1 & $(1230-1432)(0.01)$ & DSA5000 & $\mathrm{j}$ \\
\hline
\end{tabular}

a The uncertainty in speed of sound $\left(\sigma_{u}\right)$ is given in $\mathrm{m} \mathrm{s}^{-1}$ or percentage.

b Interf: interferometer; PE: pulse-echo; TOF: time of flight.

c Data is given in expression(s) form(s).

d Sample: MeC12:0 (99.2), MeC18:1 (0.6), and MeC18:2 (0.2).

e Sample: MeC12:0 (0.2), MeC14:0 (4.6), MeC16:0 (88.2); MeC17:0 (0.4), and MeC18:0 (6.3).

f Sample: MeC16:0 (1.4), MeC18:0 (0.7), MeC18:1 (5.2), MeC18:2 (86.5), and MeC18:3 (6.2).

g Two commercial samples from rapeseed oil were used.

h Rape methyl ester used in Spain.

${ }^{i}$ Rape methyl ester used in Serbia.

Samples synthesized at laboratory: soybean $(\mathrm{S})$, rapeseed $(\mathrm{R})$, palm $(\mathrm{P})$, soybean + rapeseed $(\mathrm{SR})$, palm + rapeseed $(\mathrm{PR})$, soybean + palm $(\mathrm{SP})$, soybean + rapeseed + palm (SRP), sunflower (SF); from Portuguese biodiesel producers: soybean + rapeseed (GP) and SoyA. 
Table 2

Sample material purities of the calibration standards and FAMEs.

\begin{tabular}{|c|c|c|c|c|}
\hline Material & Supplier & $\begin{array}{l}\text { Cas } \\
\text { No. }\end{array}$ & Sample purity (wt\%) & Structure/properties \\
\hline Water & & & Mili-Q & \\
\hline Toluene & Acros Organics & $142-82-5$ & 99.9 & \\
\hline 2-Butanediol & Carlo Erba & $64-17-5$ & 99.9 & \\
\hline Methyl laurate & Sigma Aldrich & $111-82-0$ & $>97$ & \\
\hline Methyl myristate & Sigma Aldrich & $124-10-7$ & $>98$ & \\
\hline Methyl palmitate & Sigma Aldrich & $112-39-0$ & $>97$ & \\
\hline Methyl stearate & Sigma Aldrich & $112-61-8$ & $>96$ & \\
\hline Methyl oleate & Sigma Aldrich & $112-62-9$ & $>99 \mathrm{GC}$ & \\
\hline Methyl linoleate & Acros Organics & $112-63-0$ & $>99$ GC & \\
\hline Cotton seed oil & Acros Organics & 17711 & $\begin{array}{l}\text { Fatty acid composition: MeC14:0 and lower: ca } 1.5 \% \text {; } \\
\text { MeC16:0 ca 25\%; MeC18:0 ca 3\%; MeC18:1, } 16 \\
\text { to } 24 \% \text {; MeC18:2, } 50 \text { to 55\%; MeC18:3 and higher < } 1.5 \%\end{array}$ & $\begin{array}{l}\mathrm{AV} \leqslant 0.5 \mathrm{mg} \mathrm{KOH} \mathrm{g}{ }^{-1} \mathrm{SV}=185-198 \mathrm{mg} \mathrm{KOH} \mathrm{g}^{-1} ; \\
\mathrm{IV}=95-115 \mathrm{~g} \mathrm{I} / 100 \mathrm{~g}, \mathrm{UM}<1.5 \% \\
n=1.4720-1.4730\left(20^{\circ} \mathrm{C}, 589 \mathrm{~nm}\right)\end{array}$ \\
\hline
\end{tabular}

$\mathrm{AV}=$ acid value; $\mathrm{SV}=$ saponification value; $\mathrm{IV}=$ iodine value; $\mathrm{UM}=$ unsaponifiable matter; $\mathrm{n}$ = refractive index.

of temperatures. Additionally, five synthetic biodiesel samples composed by different FAMEs were prepared, and also a cotton seed biodiesel sample was produced by transesterification of the cotton seed oil, then measuring the respective speed of sound. The measurements are reported at atmospheric pressure and temperatures ranging from 298.15 to $353.15 \mathrm{~K}$. The speed of sound was combined with density to calculate the isentropic and molecular compressibilities for the FAMEs and biodiesel samples studied in this work. We have also used additional information of speed of sound for FAMEs and biodiesel samples from literature to extend and complete the knowledge of the molecular compressibility. From all the collected information, predictive models of molecular compressibility and speed of sound for FAMEs and biodiesel were formulated.

\section{Experimental}

\subsection{Calibration liquids and fuels}

Water (mili-Q), toluene obtained from ACROS (Cas No: 142-82-5) with a mass fraction purity of $99.9 \mathrm{wt} \%$, and 2-butanediol from Carlo Erba (Cas No. 64-17-5) with a stated mass fraction of $99.9 \mathrm{wt} \%$ have been used as speed of sound calibrant liquids in the cell. The liquids were previously degassed ultrasonically.

The methyl esters (MeC12:0, purity $\geqslant 97 \%$, wt\%), (MeC14:0, purity $\geqslant 98 \%$ ), (MeC16:0, purity $\geqslant 97 \%$ ), (MeC18:0, purity $\geqslant 96 \%$ ), (MeC18:1, purity $\geqslant 99 \%$, GC grade), were purchased from Sigma Aldrich and (MeC18:2, purity $\geqslant 99 \%, G C$ ) from Acros Organics. All the FAMEs were used without further purification. Five synthetic biodiesel samples were prepared from known masses of FAMEs (MeC14:0, MeC16:0, MeC18:0 MeC18:1, and MeC18:2). Also, one biodiesel sample was produced by trasesterification of cottonseed oil, which was supplied by Acros Organic. The detailed specifications of all materials are summarized in Table 2.

\subsection{Synthetic samples and cottonseed biodiesel preparation}

The composition choice for the synthetic samples was based on the availability of their experimental cetane number once we intend to study this important parameter in a future work. The idea was to choose samples that could allow covering a wide range of cetane numbers, with specifications of regulatory standards. Methyl esters were mixed in appropriate mass proportions to simulate the target biodiesel samples. The biodiesel samples were prepared as follows: the synthetic cottonseed (SCS) biodiesel was based on the compositions reported by Wadumesthrige et al. [20]; the synthetic beef tallow (SBT) was from the composition given by Ramirez-Verduzco et al. [21]; synthetic biodiesel poultry fat
Table 3

Biodiesel composition (wt\%) of biodiesel of this study.

\begin{tabular}{lrrrrrr}
\hline Biodiesel FAME & \multicolumn{1}{c}{ SCS $^{\mathrm{a}}$} & \multicolumn{1}{c}{ SBT $^{\mathrm{b}}$} & \multicolumn{1}{c}{ SPF $^{\mathrm{C}}$} & SYG1 $^{\mathrm{d}}$ & SYG2 $^{\mathrm{d}}$ & PCS $^{\mathrm{e}}$ \\
\hline MeC14:0 & 0.93 & 0.50 & 0.94 & 0.00 & 2.83 & 0.01 \\
MeC16:0 & 24.98 & 17.00 & 25.56 & 11.90 & 28.57 & 26.76 \\
MeC18:0 & 2.66 & 9.41 & 7.83 & 14.43 & 13.07 & 2.81 \\
MeC18:1 & 18.48 & 31.24 & 36.34 & 72.46 & 46.60 & 17.89 \\
MeC18:2 & 52.94 & 41.85 & 29.32 & 1.21 & 8.92 & 51.60 \\
\hline
\end{tabular}

a SCS: synthetic cotton seed oil.

b SBT: synthetic beef tallow.

c SPF: synthetic biodiesel poultry fat.

d SYG1 and SYG2: synthetic samples from yellow grease.

e PSB: Produced cottonseed biodiesel.

(SPF) was obtained from composition reported by Wadumesthrige et al. [20]; two synthetic samples from yellow grease (SYGI and SYGII), obtained from cooking oil used in "fast food" were prepared from the composition reported by Kinast [22] and Canacki and Gerpen [23], respectively. The composition of synthetic biodiesel samples are presented in Table 3. The transesterification of cottonseed oil was carried out in a $50 \mathrm{ml}$ three-necked double wall jacketed reactor. The reactor was equipped with a reflux condenser, to avoid methanol losses, a magnetic stirrer, a digital thermometer (ERTCOEUTECHNICS Model 4400 Digital thermometer) and one stopper to feed the raw materials. The reactor was initially charged with a known amount of oil. A solution of known amount of catalyst sodium methoxide was prepared in the required amount of methanol and was added to the oil sample. After proper closing of the flask the temperature in the reactor was maintained constant by circulating water from a thermostatic bath (Digiterm 100 JP SELECTA). The system was also kept airtight to prevent the loss of alcohol. The reaction mix was held at a temperature just above the boiling point of the alcohol i.e. around $65^{\circ} \mathrm{C}$ to speed up the reaction. The reaction time was $2 \mathrm{~h}$. Excess alcohol was normally used to ensure total conversion of the oil to its esters. After the confirmation of completion of methyl ester formation, the heating was stopped and the products were cooled and transferred to a separating funnel. The ester layer containing mainly methyl esters and methanol and the glycerol layer containing mainly glycerol and methanol were separated. The methyl esters were washed and dried under vacuum to remove traces of moisture.

\subsection{Analyticalmethods}

The FAMEs of biodiesel produced from cottonseed oil supplied by Acros Organic, was analyzed by gas chromatography in a TRE METRICS 9001 gas chromatograph equipped with a $30 \mathrm{~m}$ fused silica capillary column DB-225 (J \& W Scientific), Agilent with a 
length of $30 \mathrm{~m}$, with $0.15 \mu \mathrm{m}$ film, and an internal diameter of $0.25 \mathrm{~mm}$. A sample $(1 \mu \mathrm{l})$ was injected at temperature of $280^{\circ} \mathrm{C}$ and without split. Helium was used as the carrier gas at a flow rate of $1 \mathrm{ml} \mathrm{min}^{-1}$ and also used as auxiliary gas for the FID. The following temperature ramp was used: initial temperature of $70^{\circ} \mathrm{C}$ during $1 \mathrm{~min}$, followed by an increase of $10^{\circ} \mathrm{C} \mathrm{min}-1$ up to $180^{\circ} \mathrm{C}$ and then $3^{\circ} \mathrm{C} \mathrm{min}{ }^{-1}$ up to $220^{\circ} \mathrm{C}$, which was maintained for $15 \mathrm{~min}$. The components in the product were quantified by using heptadecanoate methyl ester as an internal standard. Calibration was done using different concentrations of each methyl esters in $n$-heptane with addition of internal standard. The composition of the cotton seed biodiesel (PCS) is presented in Table 3.

\subsection{Sound speed measurement}

The measurement of the ultrasound velocity can provide useful information about the physicochemical behavior of liquids and liquid mixtures. Several relations and semi-empirical approaches are available in literature for the calculation of the ultrasound velocity in liquid and liquid mixtures.

In order to measure the ultrasound propagation velocity in the esters and biodiesel fuels a cell was used. A schematic of that cell is shown in Fig. 1a inserted in the measurement system and its construction details can be observed in Fig. 1b. The cylindrical cell is composed by a stainless steel hollow having diameter and length of $12 \mathrm{~mm}$ and $15.5 \mathrm{~mm}$, respectively to accommodate the testing liquids. Two $5 \mathrm{MHz}$ ultrasonic transducer are mounted in cavities drilled on the cell plane surfaces, one acting as a transmitter and the other as a receiver. To minimize reflections, the transducers are in contact with the stainless steel walls of the cavities, and silicone oil is used to enhance the wave transmission.

A wide band pulse generator is used to excite the transmitter transducer. The acoustical wave propagates through the testing liquid and is collected by the receiver. Then, the signal is amplified and displayed in the oscilloscope, and transferred to the computer for processing (see Fig. 1a). An A-scan representation of a signal corresponding to the propagation over the media between the transmitter and the receiver is shown in Fig. 2. The time of flight $\Delta \tau$ in the testing sample is obtained from the difference between the emitter-receiver propagation time and the propagation time in the steel walls (see Fig. 2). The cell was calibrated by measuring $\Delta \tau$ in water, toluene and 2-butanediol at atmospheric pressure, over the full range of temperatures $T=(298.15-343.15) \mathrm{K}$ and $u=(1117-1602) \mathrm{m} \mathrm{s}^{-1}$ using a total of $22(T, u)$ data points for

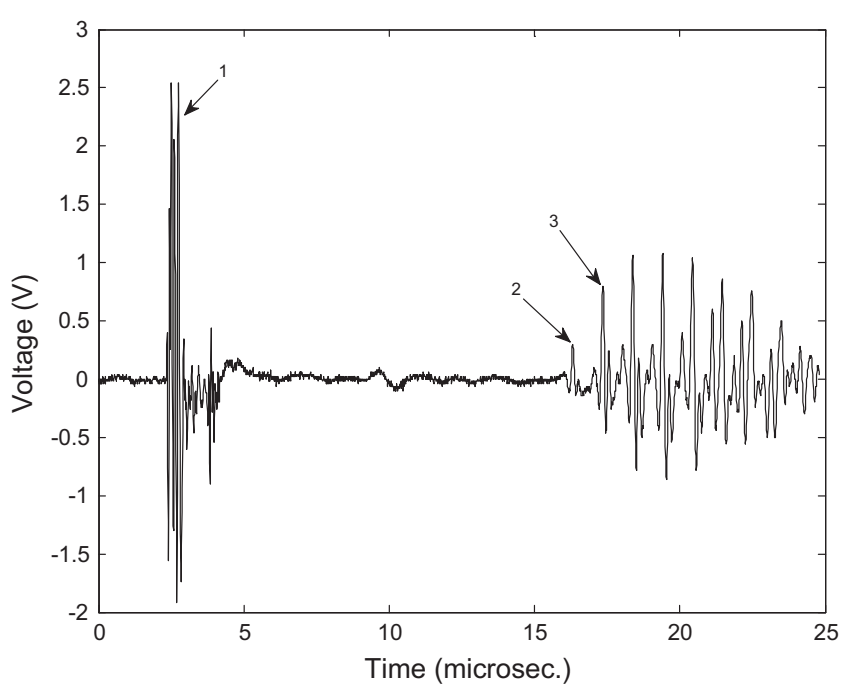

Fig. 2. S A-scan signal: (1) Emission signal; (2) receiving signal; (3) steel wall reflected signal.

these liquids (water [24], toluene [25], and 2-butanediol [26]). The literature $u(T)$ data were fitted using the following equation:

$\frac{1}{u}=\left(c_{1}+c_{2} T\right)+\left(c_{3}+c_{4} T\right) \Delta \tau$

where $c_{1}=\left(-1.84069 \times 10^{-4} \pm 3.1489 \times 10^{-5}\right) \mathrm{m}^{-1} \mathrm{~s}, c_{2}=(3.45446 \times$ $\left.10^{-7} \pm 9.8981 \times 10^{-8}\right) \mathrm{m}^{-1} \mathrm{~s} \mathrm{~K}^{-1}, c_{3}=(64.0477 \pm 2.0235) \mathrm{m}^{-1}$, and $c_{4}=\left(-3.17784 \times 10^{-2} \pm 6.3000 \times 10^{-3}\right) \mathrm{m}^{-1} \mathrm{~K}^{-1}$. The obtained correlation coefficient and standard deviation were $R=1.000$ and $\sigma= \pm 6.30 \times 10^{-7} \mathrm{~m}^{-1} \mathrm{~s}$, respectively. In terms of speed of sound the standard deviation and absolute average deviation $\mathrm{AAD} \%$ are defined as:

$\sigma=\left[\sum_{i=1}^{N_{p}}\left(u_{c a l}-u_{\exp }\right)_{i}^{2} / N_{p}\right]^{1 / 2}$

$A A D \%=\left(100 / N_{p}\right) \sum_{i=1}^{N_{p}}\left|u_{\text {cal }} / u_{\exp }-1\right|_{i}$

where the subscripts "exp" and "cal" are used for experimental and calculated values ( $v d$. Eq. (1)), respectively, and $N_{p}$ is the number of

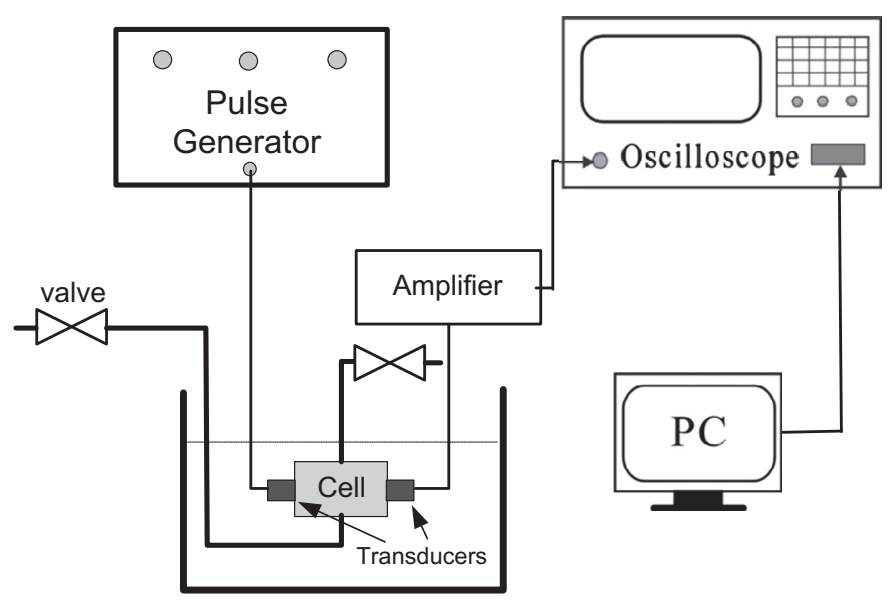

(a)

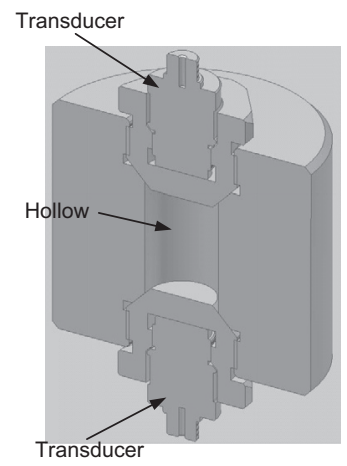

(b)

Fig. 1. Scheme of speed of sound measurement system. (a) Ultrasound cell and peripheral equipment. (b) Ultrasound cell details. 
data points. The values $\sigma= \pm 1.2 \mathrm{~m} \mathrm{~s}^{-1}$ and $\mathrm{AAD} \%=0.07 \%$ were obtained.

\section{Results and discussion}

\subsection{Sound speed}

The speed of sound measured at extended ranges of temperature for several FAMEs and biodiesel here studied are given in Table 4. The following polynomial expression, the equation:

$u=\sum_{i=0}^{2} u_{i} T^{i}$

was fitted to the experimental $(T, u)$ and the obtained coefficients $u_{i}$ are shown in Table 5. The coefficient of correlation, the low standard deviation and $\mathrm{AAD} \%$ values reveal the good quality of measured data $(T, u)$. The second degree polynomial accounts for the slight curvature sometimes observed in $(T, u)$ data. This behavior is particularly seen for water used here as calibration fluid. The experimental speed of sound for the studied samples, calculated from the A-Scan data (see Fig. 2) versus temperature are illustrated in Fig. 3. The melting points of the FAMEs given by Knothe and Dunn [27] are also shown. It can be seen that the speed of sound decreases with the increase of temperature as expected, with almost the same slopes, and the saturated and unsaturated MeC18 show similar values of speed of sound, where the differences are less than $10 \mathrm{~m} \mathrm{~s}^{-1}$. This is important because most of biodiesel systems are formed mainly by MeC18 FAMEs of several degrees of saturation. The speed values for biodiesel at a given temperature are similar to those of MeC18 FAMEs as illustrated in Table 4. The experimental speed of sound values were compared with the ones from literature (see Figs. 4-6). It can be affirmed that the sound speed values obtained in this work are in agreement with the ones provided by the literature, presenting relative deviations less than $0.3 \%$, which corresponds ca. $4 \mathrm{~m} \mathrm{~s}^{-1}$, except for the results by Tat and van
Gerpen [11]. The experimental speed of sound in synthetic samples and in the produced cottonseed biodiesel are shown in Fig. 7. It can be observed that they fall in a narrow range of $c a .11 \mathrm{~m} \mathrm{~s}^{-1}$, and this range is almost independent of the temperature. The experimental values of Freitas et al. [12] for soy and palm methylic biodiesel were included for purpose of comparison. All the other biodiesel samples studied by Freitas et al. have $(T, u)$ values into the before mentioned speed of sound range.

\subsection{Molar compressibility}

An important parameter in the study of liquid state is the molar compressibility also called Wadás constant [28] defined by

$k_{m}=\frac{M}{\rho} k_{S}^{-1 / 7}$

where $M$ is the molar mass, $k_{S}$ the isentropic compressibility, and $\rho$ the density. The isentropic compressibility $k_{S}$ is calculated from the Laplace equation:

$k_{S}=\left[\frac{1}{\rho}\left(\frac{\partial \rho}{\partial p}\right)_{S}\right]=\frac{1}{\rho u^{2}}$

where $S$ is the entropy, and $p$ the pressure.

The molar compressibility is assumed to be independent of the temperature in liquids and it is obtained from integration of the differential relationship [29],

$\left(\frac{\partial \ln k_{s}}{\partial T}\right)_{P}=-7 \alpha_{p}$

where $\alpha_{P}=-(1 / \rho)(\partial \rho / \partial T)_{P}$ is the isobaric expansibility. For the saturated FAMEs MeC10:0, MeC14:0, and MeC16:0, Daridon et al. [13] found an almost constant temperature dependence of $k_{m}$ and they developed a group contribution method to predict the molecular compressibility and speed of sound for methyl and ethyl esters with an uncertainty of $\mathrm{ca} .0 .1 \%$. In this work, the experimental density data of Pratas et al. [30] were used to calculate the isentropic

Table 4

Experimental speed of sound $(u)$ for FAME, synthetic and produced biodiesels at atmospheric pressure.

\begin{tabular}{|c|c|c|c|c|c|c|c|c|c|c|c|}
\hline$T / K$ & $u /\left(\mathrm{m} \cdot \mathrm{s}^{-1}\right)$ & $T / \mathrm{K}$ & $u /\left(\mathrm{m} \cdot \mathrm{s}^{-1}\right)$ & $\mathrm{T} / \mathrm{K}$ & $u /\left(\mathrm{m} \cdot \mathrm{s}^{-1}\right)$ & $T / \mathrm{K}$ & $u /\left(\mathrm{m} \cdot \mathrm{s}^{-1}\right)$ & $T / \mathrm{K}$ & $u /\left(\mathrm{m} \cdot \mathrm{s}^{-1}\right)$ & $\mathrm{T} / \mathrm{K}$ & $u /\left(\mathrm{m} \cdot \mathrm{s}^{-1}\right)$ \\
\hline \multicolumn{2}{|l|}{$\mathrm{MeC} 12: 0$} & \multicolumn{2}{|l|}{$\mathrm{MeC} 14: 0$} & \multicolumn{2}{|l|}{ MeC16:0 } & \multicolumn{2}{|l|}{ MeC18:0 } & \multicolumn{2}{|l|}{ MeC18:1 } & \multicolumn{2}{|l|}{ MeC18:2 } \\
\hline & & & & & & & & & & 288.41 & 1434.5 \\
\hline & & & & & & & & & & 293.33 & 1414.5 \\
\hline 298.25 & 1332.3 & 298.15 & 1350.9 & & & & & 298.28 & 1389.9 & 298.15 & 1398.3 \\
\hline 303.17 & 1313.5 & 303.15 & 1331.5 & & & & & 303.79 & 1365.3 & 303.20 & 1378.5 \\
\hline 308.26 & 1293.5 & 308.17 & 1312.8 & & & & & 308.15 & 1353.3 & 308.20 & 1360.3 \\
\hline 313.15 & 1277.8 & 313.15 & 1296.6 & 313.42 & 1317.0 & & & 313.28 & 1336.0 & 313.15 & 1343.7 \\
\hline 318.15 & 1258.2 & 318.15 & 1276.4 & 318.15 & 1297.0 & & & 318.15 & 1318.2 & 318.15 & 1327.6 \\
\hline 323.17 & 1243.6 & 323.15 & 1255.3 & 323.17 & 1282.1 & 323.15 & 1297.3 & 323.15 & 1301.0 & 323.15 & 1308.3 \\
\hline 328.17 & 1224.5 & 328.15 & 1243.2 & 328.15 & 1263.4 & 328.15 & 1281.7 & 328.15 & 1282.6 & 328.34 & 1288.8 \\
\hline 333.15 & 1207.6 & 333.15 & 1228.2 & 333.15 & 1247.1 & 333.15 & 1263.1 & 333.15 & 1266.5 & 333.15 & 1272.5 \\
\hline 338.15 & 1187.5 & 338.15 & 1212.1 & 338.15 & 1231.2 & 338.15 & 1248.4 & 338.15 & 1249.2 & 338.15 & 1255.9 \\
\hline 343.15 & 1171.2 & 343.16 & 1192.7 & 343.15 & 1211.9 & 343.15 & 1230.1 & 343.15 & 1233.4 & 343.15 & 1239.0 \\
\hline 348.17 & 1156.1 & 348.15 & 1178.4 & 348.15 & 1193.3 & 348.15 & 1215.6 & 348.15 & 1215.6 & 348.15 & 1225.1 \\
\hline 353.15 & 1138.0 & 353.15 & 1162.4 & 353.15 & 1179.1 & 353.24 & 1200.1 & 353.15 & 1200.0 & & \\
\hline \multirow[t]{2}{*}{ SCS } & & SBT & & SPF & & SYG1 & & SYG2 & & PCS & \\
\hline & & & & & & & & & & 298.15 & 1394.1 \\
\hline 303.15 & 1369.2 & 303.15 & 1371.3 & 303.15 & 1371.3 & 303.38 & 1369.3 & 303.17 & 1365.2 & 303.23 & 1376.4 \\
\hline 308.15 & 1353.3 & 308.17 & 1351.3 & 308.19 & 1351.4 & 308.17 & 1352.3 & 308.18 & 1345.4 & 308.21 & 1358.3 \\
\hline 313.15 & 1335.9 & 313.15 & 1334.0 & 313.15 & 1332.1 & 313.28 & 1328.3 & 313.17 & 1326.4 & 313.15 & 1338.8 \\
\hline 318.19 & 1314.4 & 318.15 & 1317.2 & 318.15 & 1314.4 & 318.17 & 1316.3 & 318.15 & 1309.8 & 318.15 & 1322.9 \\
\hline 323.16 & 1298.2 & 323.45 & 1304.7 & 323.15 & 1297.3 & 323.22 & 1292.8 & 323.15 & 1292.8 & 323.15 & 1305.5 \\
\hline 328.16 & 1283.4 & 328.17 & 1283.4 & 328.16 & 1278.2 & 328.16 & 1279.9 & 328.19 & 1275.5 & 328.18 & 1286.1 \\
\hline 333.15 & 1264.8 & 333.17 & 1263.9 & 333.10 & 1263.1 & 333.17 & 1261.4 & 333.17 & 1258.0 & 333.15 & 1271.6 \\
\hline 338.15 & 1250.1 & 338.16 & 1250.9 & 338.18 & 1247.6 & 338.18 & 1250.1 & 338.20 & 1242.6 & 338.20 & 1253.4 \\
\hline 343.15 & 1230.1 & 343.15 & 1235.0 & 343.15 & 1231.0 & 343.16 & 1230.1 & 343.17 & 1225.3 & 343.15 & 1237.4 \\
\hline 348.18 & 1216.4 & 348.15 & 1214.8 & 348.24 & 1215.7 & 348.16 & 1213.3 & 348.18 & 1211.7 & 348.18 & 1221.1 \\
\hline 353.15 & 1203.1 & 353.15 & 1200.8 & 353.21 & 1200.8 & 353.17 & 1204.6 & 353.16 & 1194.7 & 353.17 & 1206.2 \\
\hline
\end{tabular}

The uncertainty in $u$ is less than $\pm 1 \mathrm{~m} \mathrm{~s}^{-1}$. 

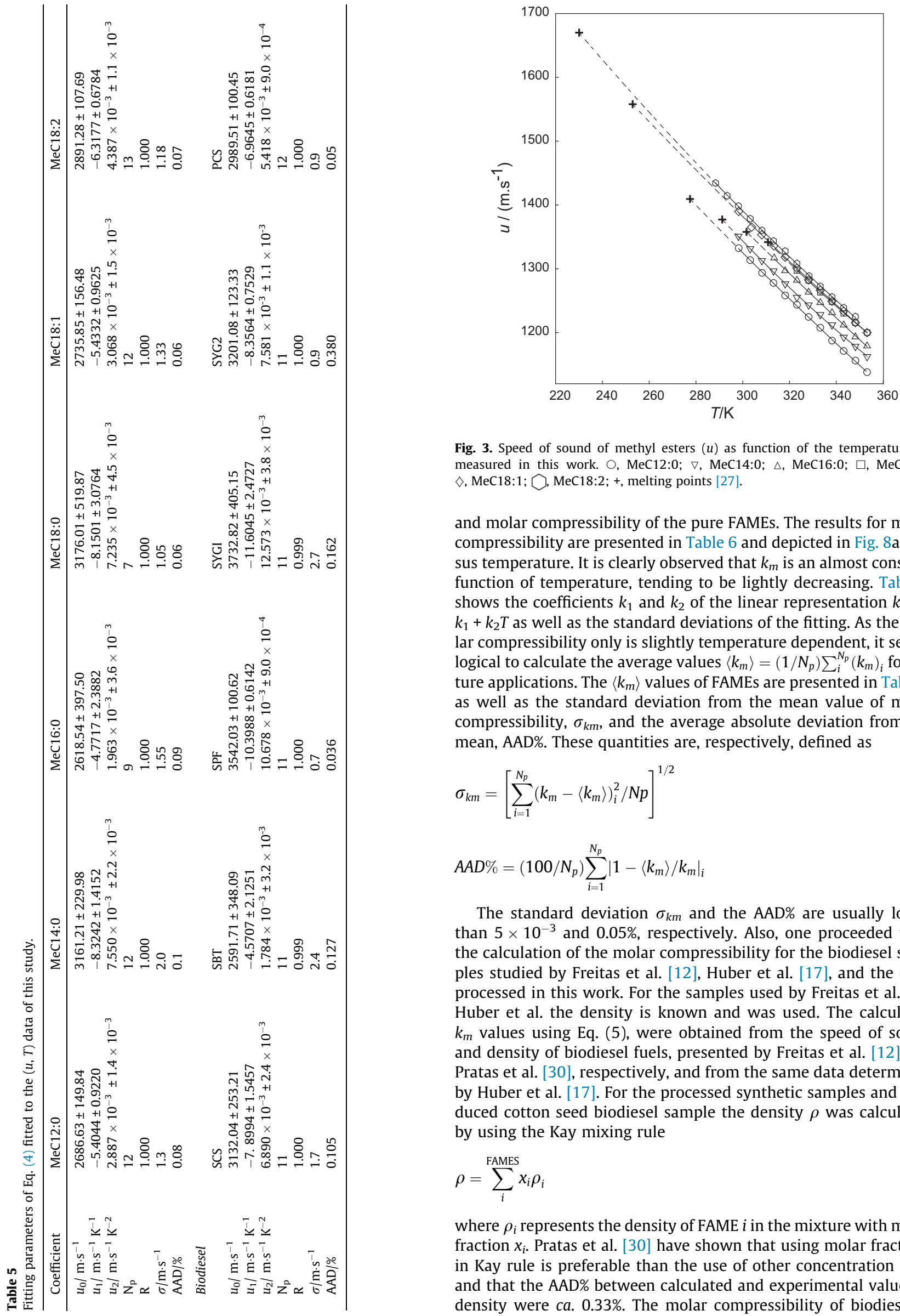

Fig. 3. Speed of sound of methyl esters $(u)$ as function of the temperature $(T)$ measured in this work. $\bigcirc, \operatorname{MeC} 12: 0 ; \nabla, \operatorname{MeC} 14: 0 ; \Delta, \operatorname{MeC16:0;} \square, \operatorname{MeC18:0}$; $\diamond, \mathrm{MeC} 18: 1 ; \bigcirc, \mathrm{MeC} 18: 2 ;+$, melting points [27].

and molar compressibility of the pure FAMEs. The results for molar compressibility are presented in Table 6 and depicted in Fig. 8a versus temperature. It is clearly observed that $k_{m}$ is an almost constant function of temperature, tending to be lightly decreasing. Table 7 shows the coefficients $k_{1}$ and $k_{2}$ of the linear representation $k_{m}=-$ $k_{1}+k_{2} T$ as well as the standard deviations of the fitting. As the molar compressibility only is slightly temperature dependent, it seems logical to calculate the average values $\left\langle k_{m}\right\rangle=\left(1 / N_{p}\right) \sum_{i}^{N_{p}}\left(k_{m}\right)_{i}$ for future applications. The $\left\langle k_{m}\right\rangle$ values of FAMEs are presented in Table 6 as well as the standard deviation from the mean value of molar compressibility, $\sigma_{k m}$, and the average absolute deviation from the mean, AAD\%. These quantities are, respectively, defined as

$\sigma_{k m}=\left[\sum_{i=1}^{N_{p}}\left(k_{m}-\left\langle k_{m}\right\rangle\right)_{i}^{2} / N p\right]^{1 / 2}$

$A A D \%=\left(100 / N_{p}\right) \sum_{i=1}^{N_{p}}\left|1-\left\langle k_{m}\right\rangle / k_{m}\right|_{i}$

The standard deviation $\sigma_{k m}$ and the AAD\% are usually lower than $5 \times 10^{-3}$ and $0.05 \%$, respectively. Also, one proceeded with the calculation of the molar compressibility for the biodiesel samples studied by Freitas et al. [12], Huber et al. [17], and the ones processed in this work. For the samples used by Freitas et al. and Huber et al. the density is known and was used. The calculated $k_{m}$ values using Eq. (5), were obtained from the speed of sound and density of biodiesel fuels, presented by Freitas et al. [12] and Pratas et al. [30], respectively, and from the same data determined by Huber et al. [17]. For the processed synthetic samples and produced cotton seed biodiesel sample the density $\rho$ was calculated by using the Kay mixing rule

$\rho=\sum_{i}^{\text {FAMES }} x_{i} \rho_{i}$

where $\rho_{i}$ represents the density of FAME $i$ in the mixture with molar fraction $x_{i}$. Pratas et al. [30] have shown that using molar fractions in Kay rule is preferable than the use of other concentration unit, and that the AAD\% between calculated and experimental values of density were ca. $0.33 \%$. The molar compressibility of biodiesel is 

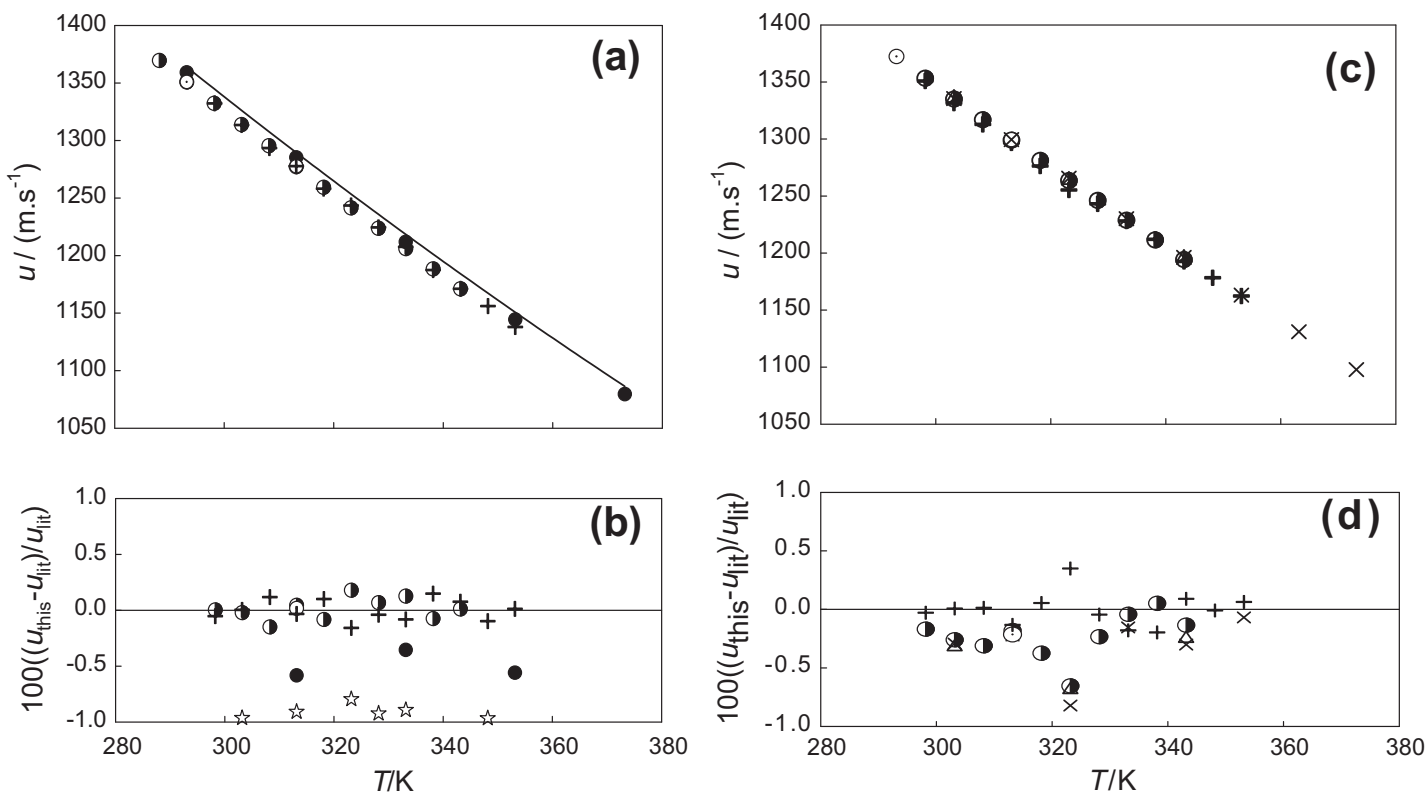

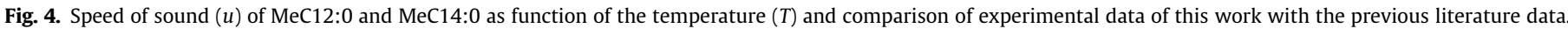

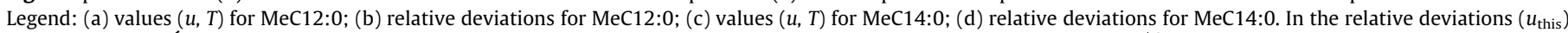

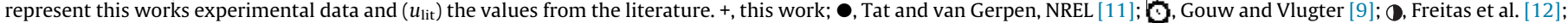

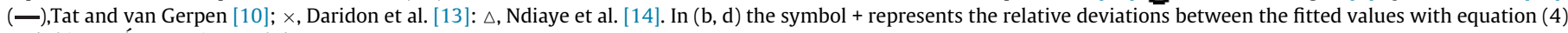
and this worḱs experimental data.
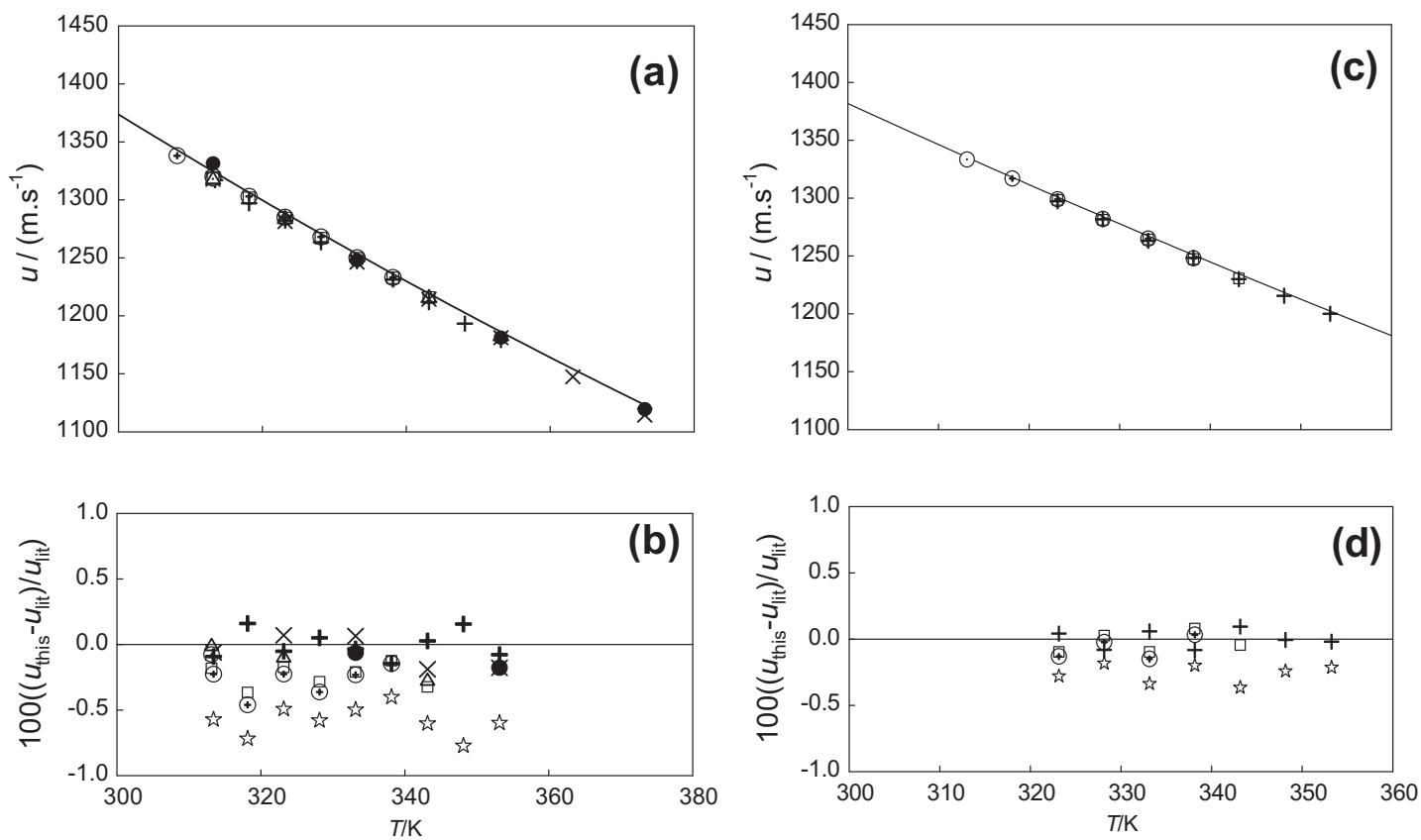

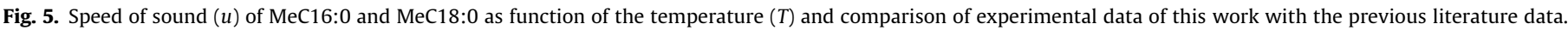

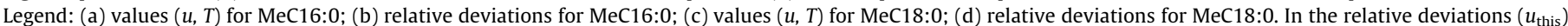

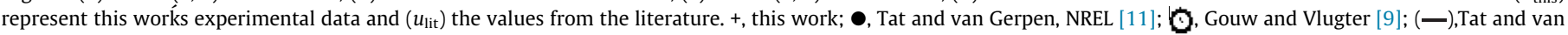

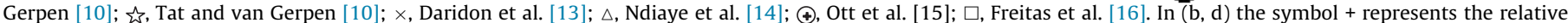
deviations between the fitted values with equation (4) and this works experimental data.

presented in Table 6 and illustrated in Fig. 8b versus temperature. A statistical analysis of the biodiesel data was also performed calculating the standard deviation and the average absolute deviation from the mean value of the molar compressibility. The results are also shown in Table 6. The analysis of Fig. 8b allows us to conclude that for biodiesel, $k_{m}$ is also slightly dependent of temperature, and this behavior is related to the nature of biodiesel sample (biodiesel composition). The standard deviation and the average absolute deviation from the mean value of $k_{m}$, are for all the biodiesel fuels, usually lower than $5 \times 10^{-3}$ and $0.05 \%$, respectively as verified for FAMEs.

Daridon et al. [13] observed a linear increase of the molar compressibility with the molecular weight for FAMEs and fatty acid ethyl esters (FAEE). This behavior is displayed in Fig. 9a, where the molar compressibility of saturated FAMEs (MeC8:0, MeC10:0, MeC12:0, MeC14:0, MeC16:0, MeC18:0) are represented as a 

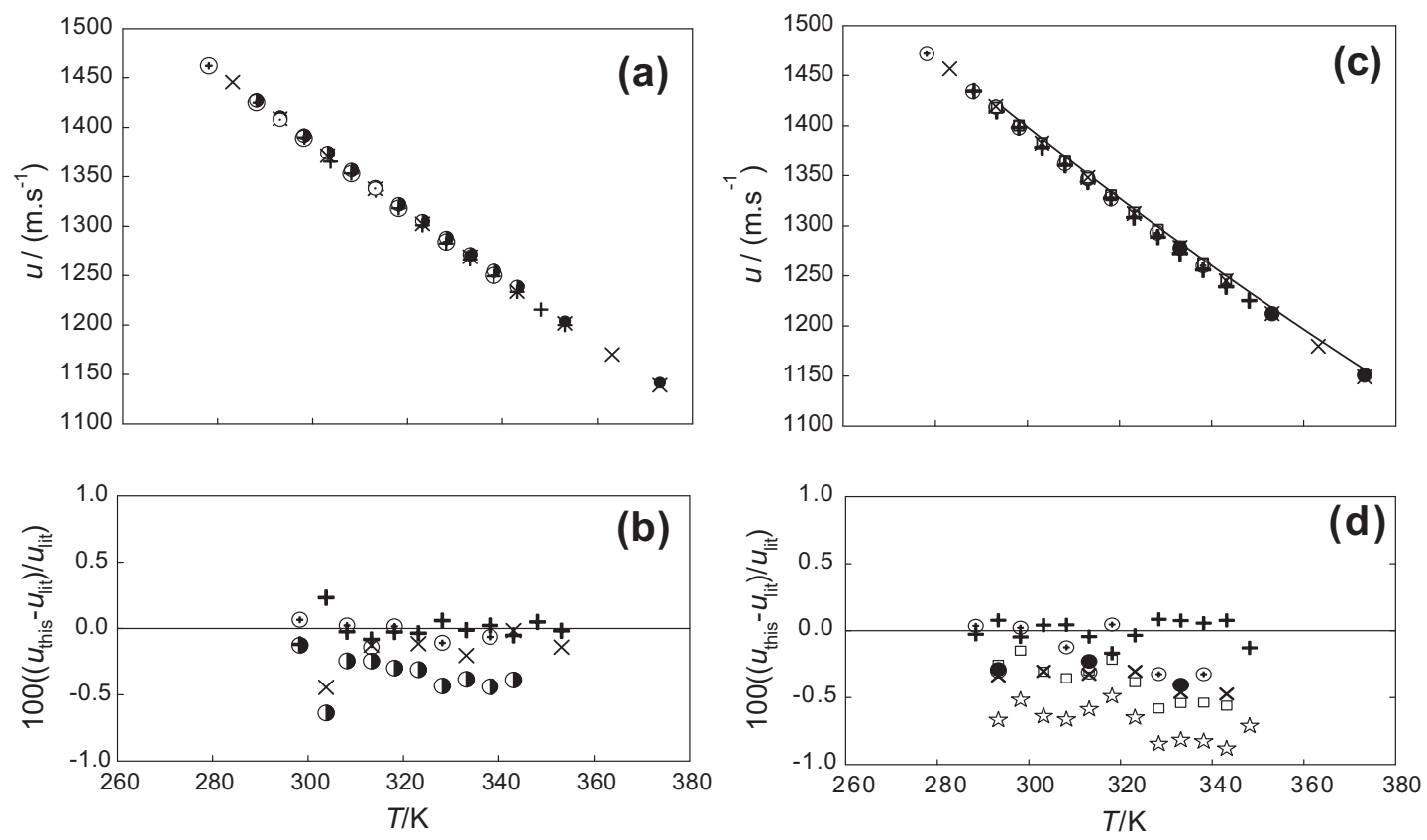

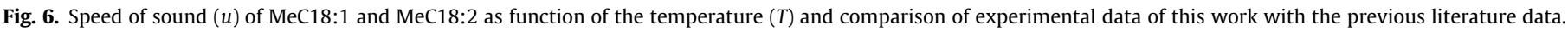

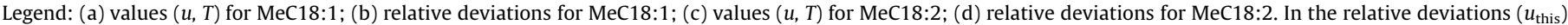

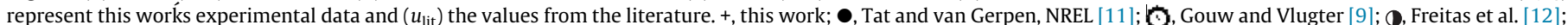

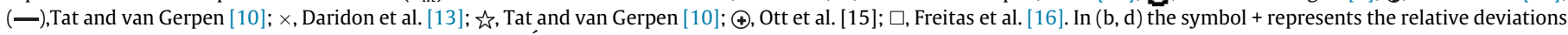
between the fitted values with equation (4) and this works experimental data.

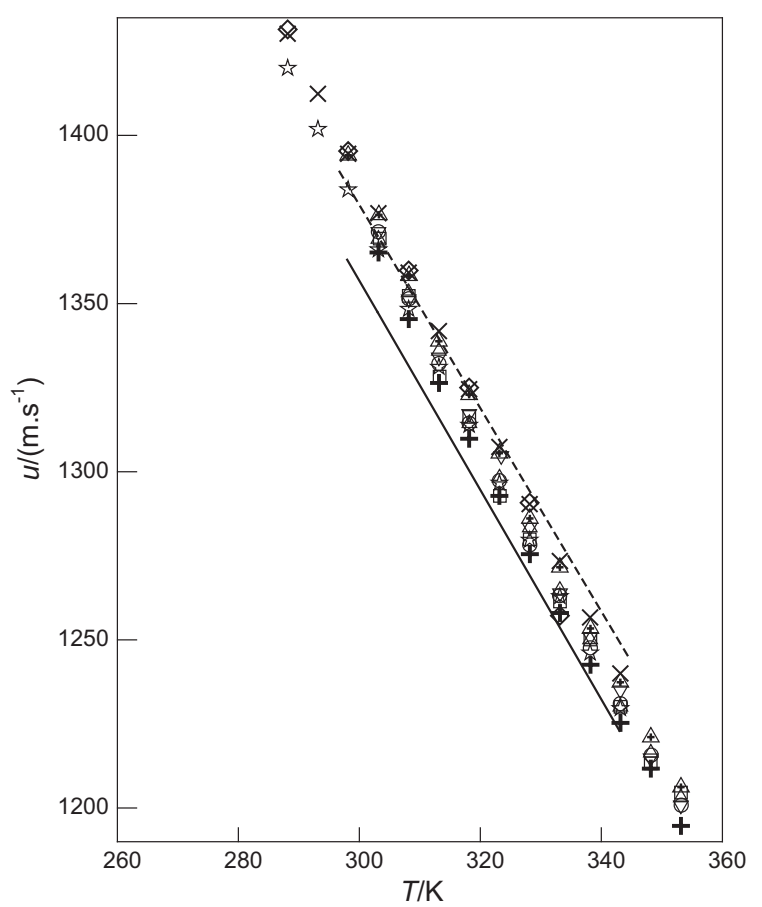

Fig. 7. Speed of sound of biodiesel $(u)$ as function of temperature $(T)$. Legend: $\triangle$, SCS; $\nabla$, SBT; O, SPF; $\square$, SYGI; +, SYGII; A, PCS; $\times$, Soy (S), Freitas et al. [12]; क子, Palm (P), Freitas et al. [12]; (-), conventional diesel, Payri et al. [18]; (--), Rapeseed biodiesel, Payri et al. [18]; $\diamond$. Huber et al.[17].

function of molecular weight $(M)$. The linear behavior can be described by the expression,

$\left\langle k_{m}\right\rangle=-(0.2825 \pm 0.0049)+\left(0.02502 \pm 2.12 \times 10^{-5}\right) M$ which correlation coefficient, standard deviation, and AAD\% are $R=1.000, \sigma= \pm 0.0025$, and $0.03 \%$, respectively. The unsaturated FAMEs MeC18:1, MeC18:2 and MC18:3 have lower values of molar compressibility than MeC18:0. Daridon et al. also observed similar straight lines for saturated FAMEs and FAEEs, which were coincidents, and also they were parallel to the corresponding line for paraffins. That means the molar compressibility is not only a function of molecular weight but depends on the molecular structure of molecules. The parallelism observed between paraffins and FAE is due to the constant contribution of the ester group for $k_{m}$ in FAE, which is independent of the ester considered [13]. Based on these results, Daridon et al. developed a group contributionmethod for the prediction of $k_{m}$ of FAE with AAD\% less than $0.05 \%$. It was checked the existence of some relationship between $k_{m}$ and $M$ for biodiesel with different compositions. In Fig. 9b the mean molar compressibility averaged to the temperature ranges of data, is represented as a function of the mean molecular weight of biodiesel, given by

$M=\sum_{i}^{\text {FAMES }} x_{i} M_{i}$

As before a linear behavior is also observed between $\left\langle k_{m}\right\rangle$ and $M$ and considering the $\left(\left\langle k_{m}\right\rangle, M\right)$ pairs for Freitas et al., Huber et al. and for our work (with the exception of SYG1 biodiesel because $\left\langle k_{m}\right\rangle$ is outside the observed range), the equation:

$\left\langle k_{m}\right\rangle=(1.5630 \pm 0.2475)+(0.01839 \pm 0.0009) M$

with correlation coefficient, standard deviation, and AAD\% of, respectively, $R=0.984, \sigma= \pm 0.0095$, and $0.11 \%$ was obtained. It is important to emphasize that this equation results from wide temperature and composition ranges of fuels. At extremes of molar weight are the values corresponding to the palm and soy biodiesel samples studied by Freitas et al. [12] presenting significant differences in composition: the palm sample $(P)$ has composition (wt\%) 
Table 6

Molar compressibility $\left(k_{m}\right)$ for FAME, synthetic and produced biodiesels.

\begin{tabular}{|c|c|c|c|c|c|c|c|c|c|c|c|}
\hline$T(\mathrm{~K})$ & $k_{m} \times 10^{3}$ & $T(\mathrm{~K})$ & $k_{m} \times 10^{3}$ & $T(\mathrm{~K})$ & $k_{m} \times 10^{3}$ & $T(\mathrm{~K})$ & $k_{m} \times 10^{3}$ & $T(\mathrm{~K})$ & $k_{m} \times 10^{3}$ & $T(\mathrm{~K})$ & $k_{m} \times 10^{3}$ \\
\hline \multirow[t]{3}{*}{ MeC12:0 } & & $\mathrm{MeC} 14: 0$ & & $\mathrm{MeC} 16: 0$ & & MeC18:0 & & MeC18:1 & & MeC18:2 & \\
\hline & & & & & & & & & & 288.41 & 6.967 \\
\hline & & & & & & & & & & 293.33 & 6.964 \\
\hline 298.25 & 5.082 & 298.15 & 5.783 & & & & & 298.28 & 7.084 & 298.15 & 6.964 \\
\hline 303.17 & 5.082 & 303.15 & 5.781 & & & & & 303.79 & 7.076 & 303.20 & 6.961 \\
\hline 308.26 & 5.080 & 308.17 & 5.780 & & & & & 308.15 & 7.080 & 308.20 & 6.959 \\
\hline 313.15 & 5.082 & 313.15 & 5.781 & 313.42 & 6.490 & & & 313.28 & 7.080 & 313.15 & 6.960 \\
\hline 318.15 & 5.080 & 318.15 & 5.778 & 318.15 & 6.484 & & & 318.15 & 7.078 & 318.15 & 6.961 \\
\hline 323.17 & 5.083 & 323.15 & 5.772 & 323.17 & 6.488 & 323.15 & 7.190 & 323.15 & 7.077 & 323.15 & 6.957 \\
\hline 328.17 & 5.081 & 328.15 & 5.779 & 328.15 & 6.485 & 328.15 & 7.192 & 328.15 & 7.074 & 328.34 & 6.953 \\
\hline 333.15 & 5.081 & 333.15 & 5.781 & 333.15 & 6.485 & 333.15 & 7.188 & 333.15 & 7.074 & 333.15 & 6.952 \\
\hline 338.15 & 5.078 & 338.15 & 5.782 & 338.15 & 6.486 & 338.15 & 7.191 & 338.15 & 7.073 & 338.15 & 6.951 \\
\hline 343.15 & 5.078 & 343.16 & 5.778 & 343.15 & 6.482 & 343.15 & 7.187 & 343.15 & 7.073 & 343.15 & 6.950 \\
\hline 348.17 & 5.080 & 348.15 & 5.781 & 348.15 & 6.478 & 348.15 & 7.190 & 348.15 & 7.070 & 348.15 & 6.953 \\
\hline 353.15 & 5.078 & 353.15 & 5.781 & 353.15 & 6.481 & 353.24 & 7.191 & 353.15 & 7.070 & & \\
\hline$\left\langle k_{m}\right\rangle$ & 5.081 & 5.780 & & 6.484 & & 7.190 & & 7.076 & & 6.958 & \\
\hline$\sigma_{k m}$ & $1.70 \times 10^{-3}$ & $2.72 \times 10^{-3}$ & & $3.24 \times 10^{-3}$ & & $1.47 \times 10^{-3}$ & & $4.07 \times 10^{-3}$ & & $5.36 \times 10^{-3}$ & \\
\hline $\mathrm{AAD}(\%)$ & 0.03 & 0.04 & & 0.04 & & 0.02 & & 0.05 & & 0.07 & \\
\hline SCS & & SBT & & SPF & & SYG1 & & SYG2 & & PCS & \\
\hline 303.15 & 6.850 & 303.15 & 6.927 & 303.15 & 6.885 & 303.38 & 7.022 & 303.17 & 6.863 & 303.23 & 6.864 \\
\hline 308.15 & 6.852 & 308.17 & 6.923 & 308.19 & 6.881 & 308.17 & 7.021 & 308.18 & 6.859 & 308.21 & 6.862 \\
\hline 313.15 & 6.851 & 313.15 & 6.923 & 313.15 & 6.878 & 313.28 & 7.011 & 313.17 & 6.857 & 313.15 & 6.859 \\
\hline 318.19 & 6.845 & 318.15 & 6.923 & 318.15 & 6.877 & 318.17 & 7.018 & 318.15 & 6.857 & 318.15 & 6.860 \\
\hline 323.16 & 6.846 & 323.45 & 6.931 & 323.15 & 6.876 & 323.22 & 7.008 & 323.15 & 6.857 & 323.15 & 6.859 \\
\hline 328.16 & 6.848 & 328.17 & 6.922 & 328.16 & 6.872 & 328.16 & 7.013 & 328.19 & 6.856 & 328.18 & 6.855 \\
\hline 333.15 & 6.845 & 333.17 & 6.918 & 333.10 & 6.874 & 333.17 & 7.010 & 333.17 & 6.854 & 333.15 & 6.858 \\
\hline 338.15 & 6.847 & 338.16 & 6.923 & 338.18 & 6.876 & 338.18 & 7.018 & 338.20 & 6.856 & 338.20 & 6.856 \\
\hline 343.15 & 6.841 & 343.15 & 6.923 & 343.15 & 6.875 & 343.16 & 7.011 & 343.17 & 6.854 & 343.15 & 6.856 \\
\hline 348.18 & 6.845 & 348.15 & 6.916 & 348.24 & 6.877 & 348.16 & 7.010 & 348.18 & 6.858 & 348.18 & 6.856 \\
\hline 353.15 & 6.849 & 353.15 & 6.919 & 353.21 & 6.878 & 353.17 & 7.022 & 353.16 & 6.856 & 353.17 & 6.857 \\
\hline$\left\langle k_{m}\right\rangle$ & 6.847 & 6.923 & & 6.877 & & 7.015 & & 6.857 & & 6.859 & \\
\hline$\sigma_{k m}$ & $3.09 \times 10^{-3}$ & $3.95 \times 10^{-3}$ & & $3.28 \times 10^{-3}$ & & $5.10 \times 10^{-3}$ & & $2.48 \times 10^{-3}$ & & $2.92 \times 10^{-3}$ & \\
\hline AAD (\%) & 0.04 & 0.04 & & 0.04 & & 0.07 & & 0.03 & & 0.04 & \\
\hline
\end{tabular}

MeC16:0 $=42.45 \%, \operatorname{MeC} 18: 1=41.92 \%$ and $\mathrm{MeC} 18: 2=9.80 \%$, while for soy sample $(S)$, MeC16:0 $=10.76 \%, \operatorname{MeC} 18: 1=22.96 \%$ and $\mathrm{MeC} 18: 2=53.53 \%$. From the data existent in the literature, it can be said that a narrow range is observed for the variation of molar weight $\left(M_{\min }=284.317\right.$ corresponding to palm diesel to $M_{\max }=295.072$ for rapeseed fuel). Considering the molar compressibility and mean molar weight values of biodiesel samples prepared by Freitas et al., Huber et al. and the ones obtained in this work, resulted by least squares fitting the equation:

$$
\begin{aligned}
k_{m}= & 6.8178-1.127 \times 10^{-4} T+F(M, T)(0.2351-6.8 \\
& \left.\times 10^{-5} T\right)
\end{aligned}
$$

with statistical parameters $R=1.000, \sigma= \pm 0.0102$, and $\mathrm{AAD} \%=0.1 \%$. In Eq. (14),

$$
\begin{aligned}
F(M, T)= & -4.284 \times 10^{-7}(M-295.07)(M-284.32) T \\
& +0.09298(M-284.32)
\end{aligned}
$$

This equation provides the accurate data of molar compressibility at molar weight limits $M_{\min }$ and $M_{\max }$, before mentioned, therefore giving bounded values of $k_{m}$. The AAD\% values from Eq. (14), related to the biodiesel fuels are given in Table 8 . The error analysis is made considering the subsets (Freitas et al., Huber et al. and the ones obtained in this work), justified by the different variation range of sound speed versus temperature (see Fig. 7) and the different composition of fuels for the subsets. The results of Eq. (14) can be compared with those assuming the ideal mixing rule defined as:

$k_{m}=\sum_{i}^{\text {FAMES }} x_{i} k_{m, i}$ where $k_{m, i}$ are the molar compressibility of the FAMEs. Due to the lack of experimental sound speed data for some minority FAMEs allowing the calculation of the molar compressibility, then in this work a pseudo-component concept similar to that applied by Freitas et al. [12] to the speed of sound was adopted: the molar compressibility of $\mathrm{C} 16: 1$ was supposed as that of MeC16:0, that of MeC20:0, MeC22:0 and MeC24:0 as that of MeC18:0 and for MeC20:1 and MeC22:1 as that for C18:3. For methyl caprate (MeC10:0), the speed of sound provided by Daridon et al. [13] for temperatures ranging from $283.15 \mathrm{~K}$ to $343.15 \mathrm{~K}$ and density measured by Pratas et al. [31], were used to obtain the relation $k_{m}=4.4151-1.0857 \times 10^{-4} \mathrm{~T}$. For methyl linolenate (MeC18:3) the speed of sound measured by Gouw and Vlugter [9] at temperatures of $293.15 \mathrm{~K}$ and $313.15 \mathrm{~K}$ and the density measured by Pratas et al. [32] provided a similar relation $k_{m}=6.8400$ $3.9300 \times 10^{-5} T$.

From Table 8, it can be concluded that the predictions for the molar compressibility with the simple mixing rule given by Eq. (16), provide good estimates of that parameter. For Freitas et al. and this work subset, the AAD\% is lower than $0.1 \%$. The prediction with Eq. (14) is also possible with deviations lower than $0.1 \%$ particularly for Freitas et al. subset. The predictive capacity of both methods are evaluated in term of overall average deviation, OAAD\%, defined as:

$O A A D \%=\frac{1}{N_{S}} \sum_{i=1}^{N_{S}}(A A D \%)_{i}$

where the subscript $i$ refers to a subset with an average deviation value $(\mathrm{AAD} \%)_{i}$ for the $\left(T, k_{m}\right)$ data and $N_{s}$ is the number of systems (subsets) involved. The OAAD\% for equations (14) and (16) are 0.17 and $0.19 \%$, respectively. 

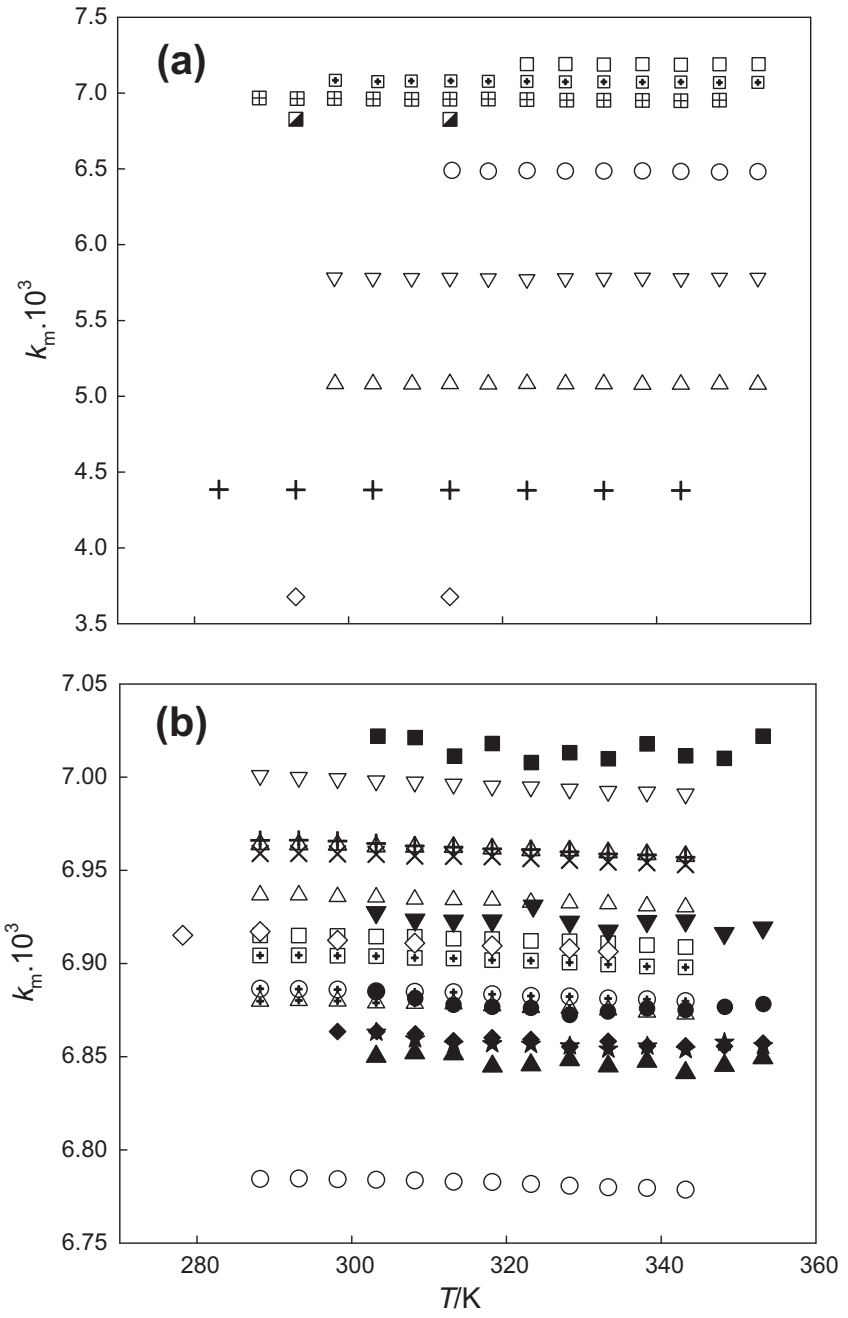

Fig. 8. Molar compressibility $\left(k_{\mathrm{m}}\right)$ of FAMES and biodiesel as a function of temperature $(T)$. (a) FAMES: $\diamond, \operatorname{MeC} 8: 0 ;+, \operatorname{MeC} 10: 0 ; \triangle$, MeC12:0; $\nabla, \operatorname{MeC} 14: 0$; O, MeC16:0; $\square$, methyl stearate; $\square$, MeC18:0; $\uparrow$, MeC18 :1; 田, MeC18:2; $\square$ MeC18:3. (b) Biodiesel: $\triangle$, soybean $(S)[12] ; \nabla$, rapeseed $(R)[12] ; O$, palm $(P)[12]$; $\triangle$, soybean+rapeseed (SR) [12]; palm+rapeseed (PR) [12]; Аि, soybean+palm (SP) $[12] ; \square$, soybean+rapeseed+palm (SRP) $[12]$; +, sunflower (SF) [12]; $\times$, (soybean+rapeseed) GP [12]; Ф, SoyA [12] ; $\diamond$, Sample A [17]; $\mathbf{\Lambda}$, SCS; $\mathbf{\nabla}$, SBT; $\bullet$, SPF;

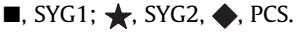

\subsection{Models for speed of sound}

From Eq. (6), the sound speed is obtained by

$u=\rho^{3}\left(\frac{k_{m}}{M}\right)^{7 / 2}$

Therefore the sound speed can be calculated from the molar compressibility, density and molecular weight. As the molar compressibility can be considered as constant in wide ranges of temperatures $\left\langle k_{m}\right\rangle$ can be used in Eq. (18), giving

$u=\rho^{3}\left(\left\langle k_{m}\right\rangle / M\right)^{7 / 2}$
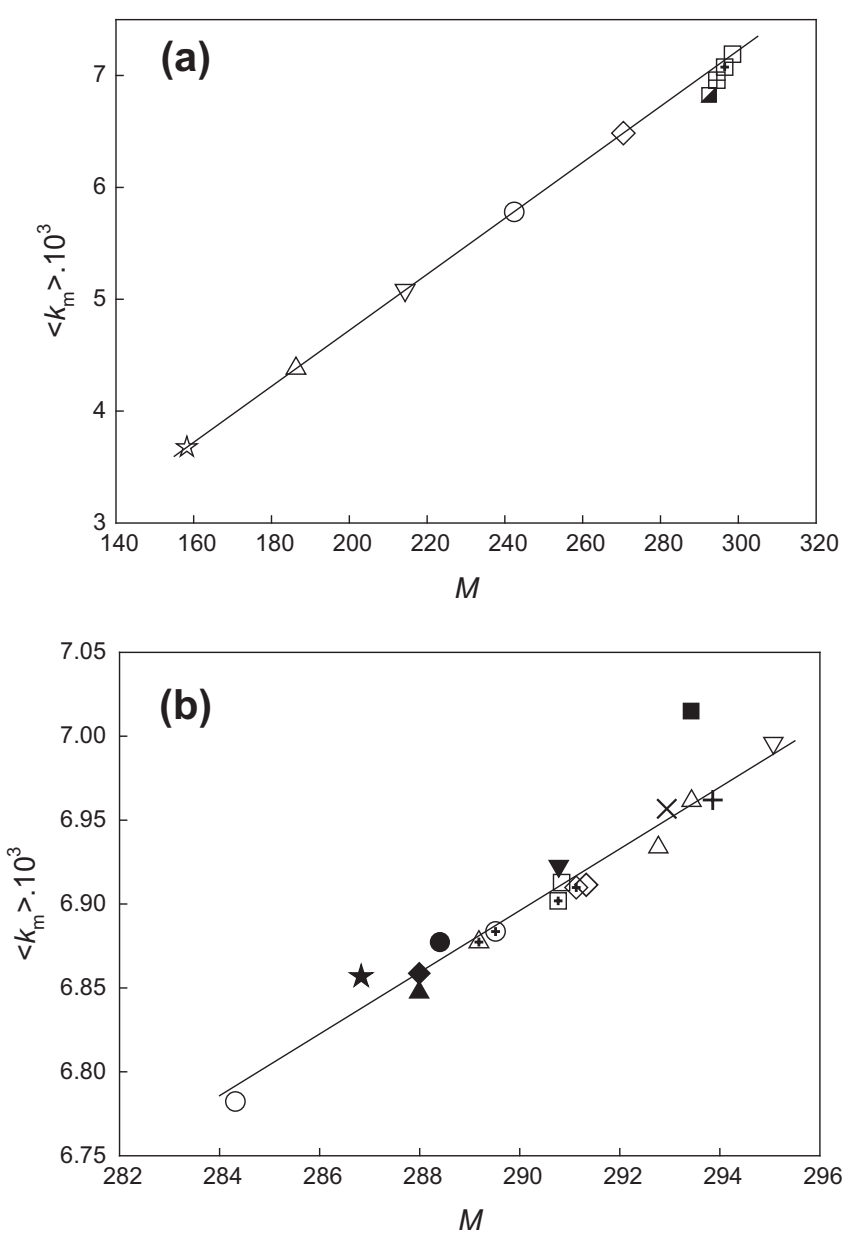

Fig. 9. Relation between molar compressibility $\left(k_{\mathrm{m}}\right)$ and molecular weight $(M)$. (a) FAMES: 弥, MeC8:0; $\triangle$, MeC10:0; $\nabla$ MeC12:0; O, MeC14:0; $\diamond, \mathrm{MeC}: 16 ; \square, \mathrm{MeC} 18: 0$;

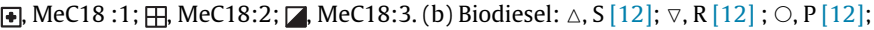
$\triangle$, SR [12]; ^. PR [12]; ^, SP [12]; $\square$, SRP [12]; +, Sf [12]; ×, GP [12]; $\oplus$, SoyA [12]; $\diamond$. Sample A and $\diamond$, Sample B [17]; $\Delta, S C S ; \nabla$, SBT; $\bullet$, SPF; $\mathbf{\square}$, SYG1; $\downarrow$, SYG2, PCS.

The density of FAMEs can be accurately calculated [31,32] or predicted while Kay mixing rule given by Eq. (10) can be used for biodiesel samples. Thus, Eq. (19) can be used to predict the speed of sound in FAMEs and biodiesel. The comparison between the sound speed calculated by Eq. (19) using Eq. (11) for $\left\langle k_{m}\right\rangle$, and experimental ones for saturated FAMES are given in Fig. 10. The individual AAD\% values are expressed by Eq. (3), and are usually less than $0.20 \%$ ( $c a .3 \mathrm{~m} \mathrm{~s}^{-1}$ ), which is not far from the experimental error found in the measurements. For the saturated FAMEs the overall average relative deviation OAAD\% was calculated by Eq. (17) where $N_{s}$ refers to the number of FAMES studied. For the FAMEs (MeC6:0 to MeC18:0), the OAAD\% $=0.15 \%\left(c a .2 \mathrm{~m} \mathrm{~s}^{-1}\right.$ ). For FAMEs not included in the fit of Eq. (11) (MeCn:0, $n=7,9$, $11,13,15,17)$ the OAAD\% in the speed of sound is $0.26 \%$ ( $c a$. $\left.3 \mathrm{~m} \mathrm{~s}^{-1}\right)$.

Eq. (19) was applied to biodiesel fuels considering also the $(T, u)$ subsets of Freitas et al. [12], Hubber et al. [17], and the six biodiesel

Table 7

Fitting parameters and standard deviation $(\sigma)$ of linear of equation fitted to the $\left(k_{\mathrm{m}}, T\right)$ data.

\begin{tabular}{|c|c|c|c|c|c|c|c|c|}
\hline Coefficients & MeC10:0 & $\mathrm{MeC} 12: 0$ & $\mathrm{MeC} 14: 0$ & $\mathrm{MeC} 16: 0$ & MeC18:0 & MeC18:1 & MeC18:2 & $\mathrm{MeC} 18: 3$ \\
\hline$k_{1}$ & $4.4151 \pm 0.0031$ & $5.1007 \pm 0.0081$ & $5.7805 \pm 0.0163$ & $6.5523 \pm 0.0187$ & $7.1962 \pm 0.0219$ & $7.1455 \pm 0.0104$ & $7.0448 \pm 0.0086$ & 6.8400 \\
\hline$k_{2} 10^{5}$ & $-10.8571 \pm 0.9939$ & $-6.2091 \pm 2.4734$ & $-0.2170 \pm 4.9955$ & $-20.3650 \pm 5-6001$ & $-1.8152 \pm 6.4877$ & $-21.4394 \pm 3.1809$ & $-27.300 \pm 2.7127$ & -3.9300 \\
\hline$\sigma$ & 0.001 & 0.002 & 0.003 & 0.002 & 0.002 & 0.002 & 0.002 & 0 \\
\hline
\end{tabular}


Table 8

Error analysis of molar compressibility and speed of sound predictions by different methods.

\begin{tabular}{|c|c|c|c|c|c|c|c|c|c|c|}
\hline \multirow[t]{2}{*}{ Biodiesel } & \multicolumn{3}{|c|}{$\mathrm{AAD} \%\left(k_{\mathrm{m}}\right)$} & \multicolumn{7}{|c|}{$\mathrm{AAD} \%(\mathrm{u})$} \\
\hline & Eq. (14) & Eq. (16) & ID & VD & NMT & $\mathrm{CT}$ & MC1 & MC2 & $\mathrm{JJ}$ & IMP \\
\hline$S^{a}$ & 0.24 & 0.04 & 0.23 & 0.31 & 0.22 & 0.22 & 0.23 & 0.40 & 0.24 & 0.22 \\
\hline $\mathrm{R}^{\mathrm{a}}$ & 0.00 & 0.02 & 0.27 & 0.34 & 0.27 & 0.26 & 1.86 & 0.99 & 0.28 & 0.26 \\
\hline $\mathrm{P}^{\mathrm{a}}$ & 0.01 & 0.12 & 0.31 & 0.51 & 0.28 & 0.33 & 0.62 & 0.70 & 0.30 & 0.31 \\
\hline $\mathrm{SR}^{\mathrm{a}}$ & 0.03 & 0.06 & 0.34 & 0.42 & 0.34 & 0.34 & 1.01 & 0.25 & 0.35 & 0.33 \\
\hline $\mathrm{PR}^{\mathrm{a}}$ & 0.04 & 0.14 & 0.29 & 0.45 & 0.27 & 0.30 & 1.24 & 0.12 & 0.29 & 0.29 \\
\hline $\mathrm{SP}^{\mathrm{a}}$ & 0.04 & 0.11 & 0.23 & 0.40 & 0.21 & 0.24 & 0.59 & 0.39 & 0.23 & 0.22 \\
\hline $\mathrm{SRP}^{\mathrm{a}}$ & 0.01 & 0.11 & 0.31 & 0.46 & 0.29 & 0.31 & 1.02 & 0.08 & 0.31 & 0.30 \\
\hline $\mathrm{SF}^{\mathrm{a}}$ & 0.14 & 0.02 & 0.32 & 0.37 & 0.31 & 0.31 & 0.69 & 0.07 & 0.32 & 0.31 \\
\hline $\mathrm{GP}^{\mathrm{a}}$ & 0.04 & 0.13 & 0.23 & 0.31 & 0.22 & 0.22 & 0.82 & 0.08 & 0.24 & 0.22 \\
\hline Soy $A^{a}$ & 0.14 & 0.18 & 0.33 & 0.42 & 0.32 & 0.34 & 0.54 & 0.36 & 0.34 & 0.33 \\
\hline PAAD\% & 0.07 & 0.09 & 0.28 & 0.40 & 0.27 & 0.29 & 0.86 & 0.34 & 0.26 & 0.22 \\
\hline $\mathrm{HA}^{\mathrm{b}}$ & 0.18 & 0.31 & 0.40 & 0.45 & 0.39 & 0.40 & 0.74 & 0.08 & 0.41 & 0.39 \\
\hline $\mathrm{HB}^{\mathrm{b}}$ & 0.14 & 0.52 & 0.37 & 0.43 & 0.37 & 0.37 & 1.12 & 0.32 & 0.38 & 0.37 \\
\hline PAAD\% & 0.16 & 0.42 & 0.39 & 0.44 & 0.38 & 0.39 & 0.93 & 0.06 & 0.40 & 0.38 \\
\hline $\mathrm{SCS}^{\mathrm{C}}$ & 0.10 & 0.05 & 0.15 & 0.24 & 0.14 & 0.15 & 0.58 & 1.49 & 0.15 & 0.14 \\
\hline $\mathrm{SBT}^{\mathrm{C}}$ & 0.19 & 0.04 & 0.14 & 0.20 & 0.14 & 0.14 & 0.63 & 0.34 & 0.14 & 0.14 \\
\hline $\mathrm{SPF}^{\mathrm{C}}$ & 0.21 & 0.05 & 0.16 & 0.29 & 0.14 & 0.17 & 0.58 & 0.50 & 0.15 & 0.15 \\
\hline SYG $^{\mathrm{C}}$ & 0.76 & 0.06 & 0.20 & 0.22 & 0.20 & 0.20 & 2.78 & 1.55 & 0.20 & 0.20 \\
\hline $\mathrm{SYG}^{\mathrm{C}}$ & 0.37 & 0.03 & 0.10 & 0.18 & 0.11 & 0.10 & 0.95 & 0.30 & 0.10 & 0.10 \\
\hline $\mathrm{PCS}^{\mathrm{c}}$ & 0.06 & 0.15 & 0.52 & 0.64 & 0.49 & 0.54 & 0.14 & 0.96 & 0.52 & 0.51 \\
\hline PAAD\% & 0.28 & 0.06 & 0.21 & 0.30 & 0.20 & 0.21 & 0.94 & 0.86 & 0.21 & 0.21 \\
\hline OAAD\% & 0.17 & 0.19 & 0.29 & 0.38 & 0.28 & 0.30 & 0.91 & 0.42 & 0.29 & 0.27 \\
\hline
\end{tabular}

a Freitas et al. [12].

b Hubbet et al. [17].

c Biodiesel fuels of this work. ID: ideal mixture; VD: van Dael; CT: Collision theory; MC1: Eq. (19) with density by Eq. (10); MC2: Eq. (19) with density of FAMEs by GCMOL method.

fuels of this work. The correlation (13) was used for the $\left\langle k_{m}\right\rangle$ calculation. The density of biodiesel was calculated in two ways because it is a fundamental property to be considered in Eq. (19). In a first method (MC1) the density was calculated by Eq. (10) using the density linear equations found by Pratas et al. [31,32] for the saturated and unsaturated FAMEs. In the second method, labeled as (MC2), the following relationship has been used,

$\rho_{B D}=\left(\sum_{i}^{\text {FAME }} x_{i} M_{i} / \sum_{i}^{\text {FAME }} x_{i} V_{m, i}\right)$

where the molar volume $V_{m, i}$ of the FAME i is calculated by GCVOL group contribution method revised by Pratas et al. [30].

Some predictive models usually used in the literature were also applied to calculate the speed of sound in biodiesel. As biodiesel is

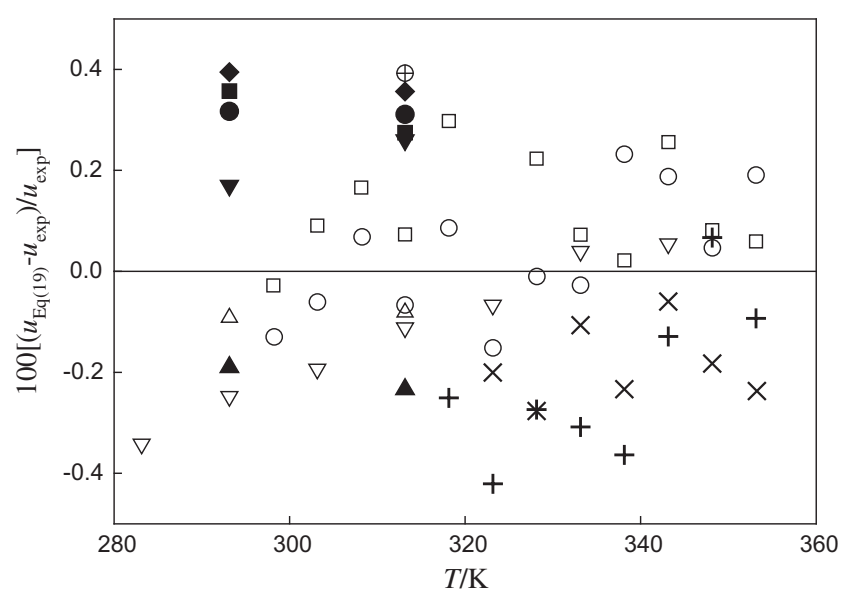

Fig. 10. Deviation between calculated speed of sound from Eq. (19) applied to FAMEs ( $\mathrm{u}_{\mathrm{EO}}$. (19)) and experimental ( $\mathrm{u}_{\mathrm{exp}}$ ). $\mathbf{\Delta}, \mathrm{MeC7}: 0 ; \triangle, \mathrm{MeC8}: 0 ; \boldsymbol{\nabla}, \mathrm{MeC} 9: 0 ; \nabla$, MeC10:0; •, MeC11:0; O, MeC12:0; $\square, \operatorname{MeC13:0;~\square ,~MeC14:0;~} \bullet$ MeC15:0; +, $\mathrm{MeC16:0;} \bigoplus, \operatorname{MeC17:0;\times ,~MeC18:0.~}$ a mixture of FAMEs of similar molar weight one can use a mixing rule assuming an "ideal" mixture behavior, as

$u_{B D}=\sum_{i}^{\text {FAME }} x_{i} u_{i}$

In Eq. (21) the sound speed of FAME $i$ was calculated for MeC12:0, MeC14:0, MeC16:0, MeC18:0, MeC18:1, and MeC18:2, using Eq. (4). For methyl caprate (MeC10:0) and methyl linolenate (MeC18:3) the $(T, u)$ data of Daridon et al. [13] and Gouw and Vlugter [9] were considered, respectively. For MeC10:0, the data have given $u=2802.4-6.2236 T+4.036 \times 10^{-3} T^{2}$ with standard deviation, $\sigma=0.24 \mathrm{~m} \mathrm{~s}^{-1}$ and for $\mathrm{MeC18:3,} \mathrm{it} \mathrm{was} \mathrm{found} \mathrm{that}$ $u=2454.3-3.5050 T$. The calculation of $u_{\mathrm{BD}}$ by Eq. (21) was made using again the pseudo-component concept similar to that applied to speed of sound by Freitas et al. [12] already explained. Other models are the equation of Van Dael [33] sometimes considered as a variation of ideal mixture, given as

$u_{B D}=\left[\left(\sum_{i}^{\text {FAME }} \frac{x_{i}}{M_{i} u_{i}^{2}}\right)\left(\sum_{i}^{\text {FAME }} x_{i} M_{i}\right)\right]^{-1 / 2}$

The Nomoto relation [34] written as

$u_{B D}=\left(\sum_{i}^{\text {FAME }} x_{i} R_{i} / \sum_{i}^{\text {FAME }} x_{i} V_{m, i}\right)$

where $R_{i}$ and $V_{m, i}$ are the molar sound speed and the molar volume of FAME $i$, respectively. The molar sound speed is defined as $R=u^{1 /}$ ${ }^{3} V_{m}$ [35]. Another model is the Schaaffs collision factor theory (CFT) [36-38]. Following this theory,

$u_{B D}=u_{\infty}\left(\left(\sum_{i}^{\text {FAME }} x_{i} S_{i}\right)\left(\sum_{i}^{\text {FAME }} x_{i} B_{i}\right) / V_{\text {mix }}\right)$

where $u_{\infty}=1600 \mathrm{~m} \mathrm{~s}^{-1}, S=\left(u V_{m}\right) /\left(u_{\infty} B\right)$ is the collision factor for the $i$ th pure FAME in the biodiesel mixture. The molar volume of the mixture $V_{\text {mix }}$ can be evaluated as $V_{\text {mix }}=\left(\sum_{i}^{F A M E} x_{i} M_{i} / \rho_{\text {mix }}\right)$ and 


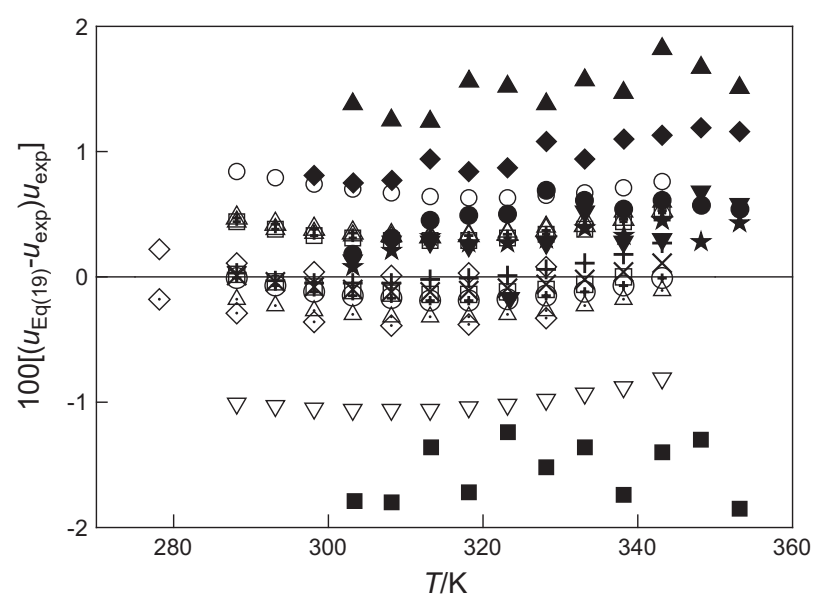

Fig. 11. Deviation between calculated speed of sound from Eq. (19) applied to biodiesel fuels $\left(u_{\mathrm{EQ}} .(19)\right)$ and experimental $\left(u_{\mathrm{exp}}\right) . \Delta, \mathrm{S}[12] ; \nabla, \mathrm{R}[12] ; \mathrm{O}, \mathrm{P}[12] ;$, SR [12]; (†, PR [12]; ^ิ, SP [12]; $\square$, SRP [12]; +, Sf [12]; $\times$, GP [12]; ๑, SoyA [12]; $\diamond$, Sample A and $\uparrow$, Sample B [17]; $\boldsymbol{\Delta}$, SCS; $\boldsymbol{\nabla}$, SBT; $\bullet$, SPF; $\mathbf{\square}$, SYG1; $九$, SYG2, $\bullet$, PCS.

$\rho_{\text {mix }}$ as evaluated using Eq. (10). $B_{i}$ is the actual volume of a molecule per mole of FAME $i$ in the biodiesel mixture which is evaluated as $B=4 / 3 \pi r^{3} N_{A}$, where $N_{A}$ is the Avogadro's number and $r$ is the molecular radius of the pure FAME, calculated as $r=\left(3 b /\left(16 \pi N_{A}\right)\right)^{1 / 3}$, where

$b=\left(\frac{M}{\rho}\right)-\left(\frac{R T}{\rho u^{2}}\right)\left[\left(1+\frac{M u^{2}}{3 R T}\right)^{1 / 2}-1\right]$

The Junjie relation [39],

$u_{B D}=\left(\sum_{i}^{\text {FAME }} x_{i} V_{m, i}\right) /\left[\left(\sum_{i}^{\text {FAME }}\left(x_{i} M_{i}\right)^{1 / 2}\right)\left(\sum_{i}^{\text {FAME }}\left(x_{i} V_{m, i} / \rho_{i} u_{i}^{2}\right)\right)^{1 / 2}\right]$

was also used to predict the speed of sound in biodiesel. Finally the speed of sound in biodiesel was also calculated based on the acoustical impedance $(\mathrm{Z}=u \rho)$,

$u_{B D}=\left(\sum_{i}^{\text {FAME }} x_{i} Z_{i} / \sum_{i}^{\text {FAME }} x_{i} \rho_{i}\right)$

The values of $\mathrm{AAD} \%$ corresponding to the various methods described before are given in Table 8. The OAAD\%, defined as in Eq. (17) with $N_{S}$ identified with the number of biodiesel subsets $\left(N_{S}=3\right)$, is also presented in Table 8 . The values of the partial AAD\% (PAAD\%), are presented for the different subsets of biodiesel fuels. The ideal mixture model which is the simplest to use, gives the same results compared with more sophisticated methods. It allows the representation of speed of sound data with OAAD $=0.29 \%$ being particularly good for our and Freitas et al. subsets. The ideal mixture method has equivalent predicting capacity as Nomoto, collision theory, Junjie, and impedance methods. The ideal mixture works better in our subset, being the individual values of AAD\% of each biodiesel fuel lower compared with Freitas et al. and Hubber et al. subsets. This is perhaps due to the largest speed of sound variation range of our samples (see Fig. 7). The ideal mixture method was applied by Freitas et al. [12] to biodiesel fuels produced from different feedstocks. They obtained an OAAD\% $=0.36 \%$. In this work the value $0.28 \%$ was obtained and the difference is explained by the wide range of temperature tested by Freitas et al.. These same authors tried another prediction method based in a modified Auerbach model [12] but the results obtained were poor, being the deviations around $1.5 \%$. It is interesting to see that Eq. (19) pro- vides different AAD\% values when different density calculation methods are used. The MC2 method which uses GCVOL group contribution gives usually lower deviations compared with MC1 one which uses Eq. (10). In our subset the deviations for PCS are higher than for the SCS although both fuels have the same composition (vd. Table 3). This is due to the higher speed of sound measured in PCS (vd. Table 4) and because it is possible that PCS contains other residual chemical species other than the detected FAMEs. The relative deviations between calculated and experimental speed of sound with the MC2 method is presented in Fig. 11. This method gives very good predictions of speed of sound particularly in Freitas et al. subset. More accurate relationships for $\left\langle k_{m}\right\rangle$ and $k_{m}$ can be possibly developed and used with GCVOL method to give accurate estimates of speed of sound in biodiesel fuels.

\section{Conclusions}

The sound speed for six fatty acid methyl ester and six biodiesel fuels were measured at temperatures ranging from 288 to $353 \mathrm{~K}$ and at atmospheric pressure using a new non-intrusive method. For the six biodiesel samples five were prepared by weight from the pure FAMEs and one was produced from transesterification of cotton seed oil being characterized by gas chromatography. The speed of sound of FAMEs and biodiesel is very well described by polynomial quadratic equations in temperature. An extensive survey of speed of sound data in the literature was used for the purpose of comparison. The results produced in this work are in close agreement with the literature ones. A particular and interesting aspect is that the biodiesel samples of this work show a large variation range of speed of sound variation at a given temperature compared with the narrow range relative to the samples measured by Freitas et al. [12]. Taking the values of the density for FAMEs together with the sound speed data, the molar compressibilities were calculated. This property is a very weak function of temperature either for FAMEs or biodiesel and can be considered as a constant depending on the substance over wide temperature ranges. Deviations from mean value are usually less than $0.05 \%$. Linear correlations were developed for mean molar compressibility as a function of molecular weight for FAMEs and biodiesel fuels withAAD\% of $0.03 \%$ and $0.11 \%$, respectively. A new correlation for the molar compressibility of biodiesel as function of mean molecular weight and temperature was developed with mean overall deviation of $0.17 \%$ taking into account subsets of data from the literature and of this work. The deviation is less than $0.1 \%$ for several biodiesel fuels. For all the biodiesel the ideal mixture model which is the simplest to use has equivalent predictive capability of sound speed in biodiesel as the more sophisticated methods. The new method developed in this work, based in mean molar compressibility and in the GCVOL group contribution for density calculation of FAMEs, gives good estimates of speed of sound. More accurate relationships for $\left\langle k_{m}\right\rangle$ and $k_{m}$ can be possibly developed and used with GCVOL method to give even more accurate estimates of speed of sound in biodiesel fuels. It is expected that the prediction methods here developed for molar compressibility and speed of sound could produce useful correlations for other biodiesel properties as the cetane number and other exhaust emission related issues.

\section{Acknowledgments}

This research is sponsored by FEDER funds through the program COMPETE - Programa Operacional Factores de Competitividade and by national funds through FCT - Fundação para a Ciência e a Tecnologia, under the project PEst-C/EME/UI0285/2013, and was also supported by a grant, EADIC II - ERASMUS MUNDUS ACTION 2 LOT 13A UE Mobility Programme 2010-2401/001-001 - EMA2“. 
The authors acknowledge the support from Eng. Maria João Bastos during the Gas Cromatography tests of biodiesel fuels undertaken in the Chemical Process Engineering and Forest Products Research Centre.

\section{References}

[1] Kumar S, Yadav JS, Sharma VK, Lim W, Cho JH, Kim J, et al. Physicochemical properties of jatropha curcas biodiesel + diesel fuel no. 2 binary mixture at $T=(288.15-308.15) \quad K$ and atmospheric pressure. J Chem Eng Data 2011;56:497-501.

[2] Benjumea P, Agudelo JR, Agudelo AF. Effect of the degree of unsaturation of biodiesel fuels on engine performance, combustion characteristics, and emissions. Energy Fuels 2011;25:77-85.

[3] Dermibas A, Dermibas I. Importance of rural bioenergy for developing countries. Energy Conv Manage 2007;48:2386-98.

[4] Ruwwe J. Metal alkoxides as catalysts for the biodiesel production. Chem Today 2008;26(1):26-8.

[5] Martyn J, Earle MJ, Plechkova NV, Seddon KR. Green synthesis of biodiesel using ionic liquids. Pure Appl Chem 2009;81:2045-57.

[6] Bournay L, Casanave D, Delfort B, Hillion G, Chodorge JA. New heterogeneous process for biodiesel production: a way to improve the quality and the value of the crude glycerin produced by biodiesel plants. Catal Today 2005;106:190-2.

[7] Pogorevc P, Kegl B, Skerget L. Diesel and biodiesel fuel spray simulations. Energy Fuels 2008;22:1266-74.

[8] Tat ME, Gerpen J. Measurement of biodiesel speed of sound and its impact on injection timing. National renewable energy laboratory 2003; NREL/SR-51031462.

[9] Gouw TH, Vlugter JC. Physical properties of fatty acid IV ultrasonic sound velocity methyl esters. J Am Oil Chem Soc 1964;41:524-6.

[10] Tat M, Gerpen J. Speed of sound and isentropic bulk modulus of alkyl monoesters at elevated temperatures and pressures. J Am Oil Chem Soc 2003;80:1249-56.

[11] Tat M, Gerpen J. Measurement of biodiesel speed of sound and its impact on injection timing. National renewable energy laboratory 2003; NREL/SR-51031462.

[12] Freitas SVD, Paredes MLL, Daridon J, Lima AS, Coutinho JAP. Measurement and prediction of the speed of sound of biodiesel fuels. Fuel 2013;103:1018-22.

[13] Daridon J, Coutinho JAP, Ndiaye H, Paredes M. Novel data and a group contribution method for the prediction of the speed of sound and isentropic compressibility of puré fatty acid methyl and ethyl esters. Fuel 2013;105:465-70.

[14] Ndiaye HI, Habrioux M, Coutinho JAP, Paredes MLL, Daridon JL. Speed of sound, density, and derivative properties of ethyl myristate, methyl myristate, and methyl palmitate under high pressure. J Chem Eng Data 2013;58:1371-7.

[15] Ott L, Huber M, Bruno T. Density and speed of sound measurements on five fatty acid methyl esters at $83 \mathrm{kPa}$ and temperatures from (278.15 to 338.15$) \mathrm{K}$. J Chem Eng Data 2008;53:2412-6.

[16] Freitas SVD, Cunha DL, Reis RA, Lima AS, Daridon JL, Coutinho JAP, et al. Application of Wada's group contribution method to the prediction of the speed of sound of biodiesel. Energy Fuels 2013;27:1365-70.

[17] Huber ML, Lemmon EW, Kazakov A, Ott LS, Bruno TJ. Model for the thermodynamic properties of a biodiesel fuel. Energy Fuels 2009;23:3790-7.
[18] Payri R, Salvador FJ, Gimeno J, Bracho G. The effect of temperature and pressure on thermodynamic properties of diesel and biodiesel fuels. Fuel 2011;90:1172-80.

[19] Nikolić BD, Kegl B, Marcović SD, Mitrović MS. Determining the speed of sound, density and bulk modulus of rapeseed oil, biodiesel and diesel fuel. Therm Sci 2012;16(Suppl. 2):S569-79.

[20] Wadumesthrige K, Smith J, Wilson J, et al. Investigation of the parameters affecting the cetane number of biodiesel. J Am Oil Chem Soc 2008;85:1073-81.

[21] Ramírez-Verduzco L, Rodríguez-Rodríguez J, Jaramillo-Jacob A. Predicting cetane number, kinematic viscosity, density and higher heating value of biodiesel from its fatty acid methyl ester composition. Fuel 2012;91(1):102-11.

[22] Kinast J. Production of biodiesel from multiple feedstocks and properties of biodiesels and biodiesel/diesel blends. National renewable energy laboratory 2003; NREL/SR-510-31460.

[23] Canacki M, Gerpen JH. Comparison of engine performance and emissions for petroleum diesel fuel, yellow grease biodiesel, and soybean oil biodiesel. Trans ASAE 2003;46:937-44.

[24] http://webbook.nist.gov/chemistry/fluid/ (assessed May 2013).

[25] Fortin T, Laesecke A, Freund M. Advanced calibration, adjustment and operation of a density and sound speed analyzer. J Chem Thermodyn 2013;53:276-85.

[26] Zorębski E, Dzida M. The effect of temperature and pressure on acoustic and thermodynamic properties of 1,4-butanediol. The comparison with 1,2-, and 1,3-butanediols. J Chem Thermodyn 2012;54:100-7.

[27] Knothe G, Dunn RO. A comprehensive evaluation of the melting points of fatty acid sand esters determined by differential scanning calorimetry. J Am Oil Chem Soc 2009;86:843-6.

[28] Wada Y. On the relation between compressibility and molal volume of organic liquids. J Phys Soc Jpn 1949;4:280-3.

[29] Mathur SS, Gupta PN, Sinhat SC. Theoretical derivation of Wadás and Raós relations. J Phys A: Gen Phys 1971;4:434-6.

[30] Pratas MJ, Freitas SVD, Oliveira MB, Monteiro SC, Lima AS, Coutinho JAP. Biodiesel density: experimental measurements and prediction models. Energy Fuels 2011;25:2333-40.

[31] Pratas MJ, Freitas S, Oliveira MB, Monteiro SC, Lima AS, Coutinho JAP. Densities and viscosities of fatty acid methyl and ethyl esters. J Chem Eng Data 2010;55:3983-90.

[32] Pratas MJ, Freitas S, Oliveira MB, Monteiro SC, Lima AS, Coutinho JAP. Densities and viscosities of minority fatty acid methyl and ethyl esters present in biodiesel. J Chem Eng Data 2011;56:2175-80.

[33] Van Dael W, Vangael E. In: 1st International conference on calorimetry and thermodynamics, Warsaw, Poland; 1969, p. 555.

[34] Nomoto O. Empirical formula for sound velocity in liquid mixtures. J Phys Soc Jpn 1958;13:1528-32.

[35] Rao MM. The adiabatic compression of liquids. J Chem Phys 1946;14:699.

[36] Schaafs W. Molekularakustik. Berlin: Springer-Verlag; 1963.

[37] Jacobson B. Ultrasonic velocity in liquids and liquid mixtures. J Chem Phys 1952;20:927-8.

[38] Nutsch-Kuhnkies R. Sound velocities of binary mixtures and solutions. Acoustica 1965;15:383-6.

[39] Junjie Z. J. China Univ Sci Tech 1984;14:298-300. 